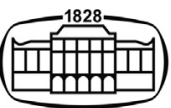

AKADÉMIAI KIADÓ

Journal of Behavioral Addictions

9 (2020) 3, 534-550

DOI:

$10.1556 / 2006.2020 .00069$

(c) 2020 The Author(s)

\section{REVIEW ARTICLE}

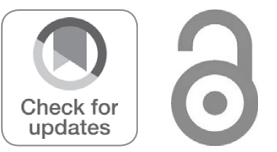

\title{
The association between the Big Five personality traits and smartphone use disorder: A meta-analysis
}

\author{
DAVIDE MARENGO ${ }^{1 *} \odot$, CORNELIA SINDERMANN ${ }^{2}$, \\ DANIELA HÄCKEL ${ }^{2}$, MICHELE SETTANNI ${ }^{1}$, JON D. ELHAI ${ }^{3,4}$ \\ and CHRISTIAN MONTAG ${ }^{2 *}$ [ \\ ${ }^{1}$ Department of Psychology, University of Turin, Turin, Italy \\ ${ }^{2}$ Department of Molecular Psychology, Institute of Psychology and Education, Ulm University, Ulm, \\ Germany \\ ${ }^{3}$ Department of Psychology, University of Toledo, Toledo, OH, USA \\ ${ }^{4}$ Department of Psychiatry, University of Toledo, Toledo, OH, USA
}

Received: April 27, 2020 • Revised manuscript received: July 5, 2020; September 4, 2020 • Accepted: September 5, 2020

Published online: October 3, 2020

\begin{abstract}
Background and aims: Personality is one of the most frequently investigated variables to shed light on the putatively addictive use of the smartphone. By investigating associations between personality and individual differences in addictive smartphone use, researchers aim to understand if some personality traits predispose technology users to develop addictive behaviors. Here, based on existing empirical literature, we aimed at determining the strength of associations between Big Five personality traits and smartphone use disorder (SmUD) by a meta-analytic approach. Method: For each Big Five personality trait, we performed a meta-analysis of correlations representing their association with SmUD. We also investigated possible publication bias and the moderating effects of age, gender, nationality, length of personality assessments, and time of publication. Results: We found $n=26$ eligible studies. In line with both the Interaction of Person-Affect-Cognition-Execution (I-PACE) model and the framework on problematic mobile-phone use by Billieux, we observed a positive association between Neuroticism and SmUD ( $\mathrm{r}=$ 0.25), while the association between Extraversion and SmUD was not significant. Partially in line with the aforementioned theoretical frameworks, Conscientiousness was negatively associated with SmUD ( $\mathrm{r}=$ -0.16 ). Remaining traits showed smaller associations. No significant publication bias emerged. Moderator analyses showed that time of publication moderated the link between Conscientiousness and SmUD. Moreover, Agreeableness and Conscientiousness showed a heightened inverse association with SmUD among older samples. Conclusions: The present meta-analysis provides robust empirical evidence that Big Five personality traits can help to understand individual differences in SmUD, supporting the usefulness of their assessment when planning and targeting interventions aimed at at-risk individuals.
\end{abstract}

\section{KEYWORDS}

personality, Big Five traits, smartphone use disorder, meta-analysis, smartphone addiction, problematic smartphone use

\section{INTRODUCTION}

*Corresponding authors.

E-mail: davide.marengo@unito.it

E-mail: christian.montag@uni-ulm.de

Since the introduction of the IPhone as the prototype of the smartphone in 2007, the world has seen a dramatic increase in the number of smartphone users. It is estimated that more than 3.5 billion people currently use a smartphone worldwide (O'Dea, 2020). Therefore, the smartphone is likely to be the technology distributed across the world faster than any other technology before. Smartphones without doubt have seen a rapid and successful distribution across the world, because they enable people to communicate efficiently via far distances, help 
to navigate in unknown territory, and provide infotainment as long as a signal is available. Although smartphones can result in greater productivity (e.g., finding your way from place A to B faster), a growing number of researchers debates potential detrimental effects of excessive smartphone use on the individual.

Most often an addiction framework has been chosen to characterize excessive smartphone use assessing symptoms such as preoccupation with smartphone use, withdrawal symptoms when not being online or productivity loss due to fragmentation of everyday life (Duke \& Montag, 2017b; Haug et al., 2015; Kwon, Kim, Cho, \& Yang, 2013; Lin et al., 2014; Rozgonjuk, Sindermann, Elhai, \& Montag, 2020; Samaha \& Hawi, 2016). Therefore, it is also not surprising that some researchers characterize excessive smartphone use as smartphone addiction, although this term is controversially debated (Billieux, 2012; Panova \& Carbonell, 2018). Moreover, a focus on excessive use of the smartphone in general might ultimately not be valid, because individuals are most likely not hooked onto the device itself, but rather to certain applications installed on their own smartphone (Pontes, Szabo, \& Griffiths, 2015). After all, an alcoholic is similarly not dependent on the bottle, but on the alcohol in the drink (Panova \& Carbonell, 2018). In line with this conceptualization, previous work shows a strong overlap between smartphone addiction and excessive use of WhatsApp (Sha, Sariyska, Riedl, Lachmann, \& Montag, 2019). Other researchers use the term problematic smartphone use (Elhai et al., 2018; Wang, Wang, Gaskin, \& Wang, 2015), but this term is also not optimal, because it is not clear whether the "problematic" aspect of problematic smartphone use represents the end-point of excessive use, or the transition from mild use to excessive use.

In line with the terminology used by the World Health Organization in the context of Gaming Disorder (Montag, Schivinski et al., 2019; Pontes et al., 2019), we currently prefer the term smartphone use disorder (SmUD) as a mobile form of Internet Use Disorders (IUDs) (Montag, Wegmann, et al., 2019). This said, we explicitly mention that SmUD represents no official diagnosis in the International Classification of Diseases 11th Revision (ICD-11) or the Diagnostic and Statistical Manual of Mental Disorders, Fifth Edition (DSM-5) and researchers should refrain from overpathologizing everyday life behavior (Billieux, Schimmenti, Khazaal, Maurage, \& Heeren, 2015). Therefore, we explicitly state that most studies in the field clearly investigated individual differences in the tendencies towards SmUD (on a subclinical level). Nevertheless, we use the SmUD term to strive for unification of terms in the field of technology use disorders in the literature; see also that other researchers use this terminology; e. g. Gao, Jia, Fu, Olufadi, and Huang (2020), Peng, Zhou, Wang, Zhang, and Hu (2020).

By looking at existing theoretical frameworks for IUDs, Big Five personality factors emerge as important variables that may also help explain individual differences in SmUD (Duke \& Montag, 2017a). The Big Five were derived against the background of a lexical approach (McCrae \& John, 1992; Montag \& Elhai, 2019; Montag \& Panksepp, 2017), which means that statistical analysis of language resulted in five personality traits with relatively stable distribution around the globe (for exceptions see discussion about non-WEIRD samples in Laajaj et al. (2019), to name a recent critique).

In the context of SmUD, we take a closer look at two theoretical frameworks: The Interaction of Person-AffectCognition-Execution (I-PACE) model on specific IUDs and Billieux's framework on problematic mobile phone use. The I-PACE model by Brand, Young, Laier, Wölfling, and Potenza (2016) posits that individual differences in IUD may be the result of a complex interaction of person, affect, cognition, and execution variables. Of note, Montag et al. (2015) and Müller et al. (2017) demonstrated that specific IUDs are associated with unspecified IUD, and Montag, Wegmann, et al. (2019) recently explained that SmUD could be seen as mobile form of IUD. In particular, the overlap between Social Networks Use Disorder/ Internet Communication Disorder (a specific IUD) and SmUD (Sha et al., 2019) provides a rationale to use the IPACE model as a theoretical framework to also study SmUD. Focusing in particular on the Person component of the I-PACE model, Brand et al. (2016) discussed the relevance of personality traits, such as low Conscientiousness and high Neuroticism as factors driving a heightened risk for IUD.

On the other hand, the theoretical model by Billieux (2012) is also noteworthy as it postulates multiple pathways linking personality traits to problematic mobile phone use (as the construct is named in the work by Billieux). In the model by Billieux, Neuroticism is expected to increase the risk of SmUD via the relationship maintenance pathway: Individuals high in Neuroticism may try to control their relationship status via compulsively checking social media and instant messaging apps. The extraversion pathway posits that individuals high in Extraversion may be inclined to heightened smartphone use in order to fulfill their urges for social interactions, although this component of the model is not expected to lead to SmUD (Billieux, Maurage, LopezFernandez, Kuss, \& Griffiths, 2015). Interestingly, in this model the role of the Conscientiousness trait is not prominently highlighted. But recent work highlights the important role of Conscientiousness in research related to SmUD (Lachmann, Duke, Sariyska, \& Montag, 2019).

Due to the prominent role of personality in both the IPACE model (Brand et al., 2016) and also the model by Billieux (2012), in the present study we aimed to synthesize existing literature concerning the association between Big Five personality factors and SmUD in the present study. In detail, we perform a meta-analysis on correlations reported in studies exploring putative links between Big Five personality factors and SmUD as assessed via self-report questionnaires. For reasons of completeness, we not only focus on the personality traits of Neuroticism and Extraversion as discussed in the model by Billieux (2012), but on all of the Big Five personality factors. This said, both the theoretical assumptions of the I-PACE model and the model by Billieux function as important guiding literature. We expect higher Neuroticism to be linked to higher SmUD 
(Billieux, 2012; Brand et al., 2016), Extraversion not to be linked to SmUD (Billieux, 2012; Brand et al., 2016), and lower Conscientiousness to be linked to higher SmUD (Brand et al., 2016). In this context, it is worthy to note that a recent meta-analysis study (Carvalho, Sette, \& Ferrari, 2018) has investigated the link between pathological personality traits, including Neuroticism, and SmUD (referred to as problematic smartphone use in the study). In the study, the authors identified a positive link between SmUD and Neuroticism, but because only two studies were included in the analyses, possible moderators of the link, as well as publication bias, remained unexplored. Further, the study did not investigate other Big Five personality traits beyond Neuroticism.

In the present paper, we first illustrate in detail our literature search strategy, and the study selection process. Following this, we provide an overview of the characteristics of selected studies, including information about demographic characteristics, sampling strategy, and validity and reliability of self-report instruments.

Next, we present the results of meta-analytical computations. Firstly, we present the meta-analytical correlations for associations between SmUD and Big Five personality factors. Next, we look at possible publication bias in the selected literature, and moderator effects. More specifically, we aim to determine the impact of certain characteristics of recruited samples (i.e., the distribution of gender, age, and nationality), in affecting the strength of associations between each personality variable and SmUD severity. Further, we acknowledge existing differences in the inventories used to assess personality, and explore the stability of emerging associations when brief vs. longer questionnaires were administered. Finally, the present work investigates whether associations between personality and SmUD changed over the years. As smartphone technology and models changed over time since their first introduction to the market, including increasingly faster mobile Internet connection capabilities, new applications and features, it is reasonable to expect that these changes may have affected the way personality traits relate to the risk of developing SmUD. With the ever-increasing features available on smartphones, we expect that their nature (in terms of functions provided to the user) can become more "addictive" for certain individuals, and this may be reflected in changes in the association between SmUD and some of the personality traits.

\section{METHODS}

\section{Literature search}

In order to identify papers investigating the association between Big Five personality traits and measures of SmUD, we followed the Preferred Reporting Items for Systematic Reviews and Meta-Analyses (PRISMA) guidelines (Moher et al., 2015) and performed multiple searches in several databases, using multiple groups of keywords. Identified papers were then screened based on specific inclusion and exclusion criteria. To perform the database searches, four of the authors collaborated in creating a list of keywords which could be used to identify papers investigating SmUD, namely smartphone addiction, addictive smartphone us*, problematic smartphone use/usage, smartphone us* disorder, smartphone overus*, excessive smartphone us*, dependenc* on smartphone, smartphone dependenc*, maladaptive smartphone us*, dysfunctional smartphone us*, smartphone abuse, addictive smartphone $u s^{*}$. When applicable, an asterisk $(*)$ was used as as a truncation symbol to search the database for multiple forms of the truncated terms. Additionally, for each of the keywords above, we created alternative versions by substituting the term smartphone with other terms that could be used to refer to smartphones, in particular among early studies, namely mobile, cell phone, cellphone, and mobile phone. The resulting group of keywords was combined with the following keywords referring to Big Five personality traits: personality, traits, big 5, big five, five factor model, extraversion, introversion, neuroticism, emotional stability, openness, conscientiousness, agreeableness, extrovert, introvert, neurotic, open, agreeable, conscientious, emotionally stable.

Using the resulting set of keywords, we conducted a broad literature search in the following databases: Scopus, ISI Web of Science, and PubMed (see Supplementary material for the full search function in Scopus format). The database literature search was finalized in March 2020. An additional search was performed by inspecting citations within publications identified as eligible to be included in this meta-analysis, as well as relevant review papers (e.g., Busch \& McCarthy, 2020; Carvalho et al., 2018). A flowchart illustrating the selection process is shown in Fig. 1.

\section{Inclusion and exclusion criteria}

Papers identified through database and reference searches were screened for the following inclusion criteria: (1) Studies were published in a peer-reviewed journal; (2) Studies had to include assessments of both SmUD, and Big Five personality traits; (3) Studies (or their authors) had to provide information about the effect size of the association between SmUD and Big Five personality traits.

Exclusion criteria were the following: (1) Studies were excluded from quantitative analyses if they did not provide effect size information, or if this information could not be obtained from the authors; (2) Studies did not assess SmUD, but only investigated frequency of smartphone use or similar constructs (e.g., time spent using smartphones, or smartphone apps); (3) Studies were performed on clinical populations; (4) Non-independence of studies. In order to resolve the issue of non-independence of studies, we deemed studies as non-independent when all of the following criteria were fulfilled: (1) Studies were performed on overlapping samples, (2) Correlations were computed between the same Big Five, and (3) SmUD measures. If we found two or more studies being non-independent based on the aforementioned criteria, the study with the largest sample was selected for inclusion in the quantitative analyses. 


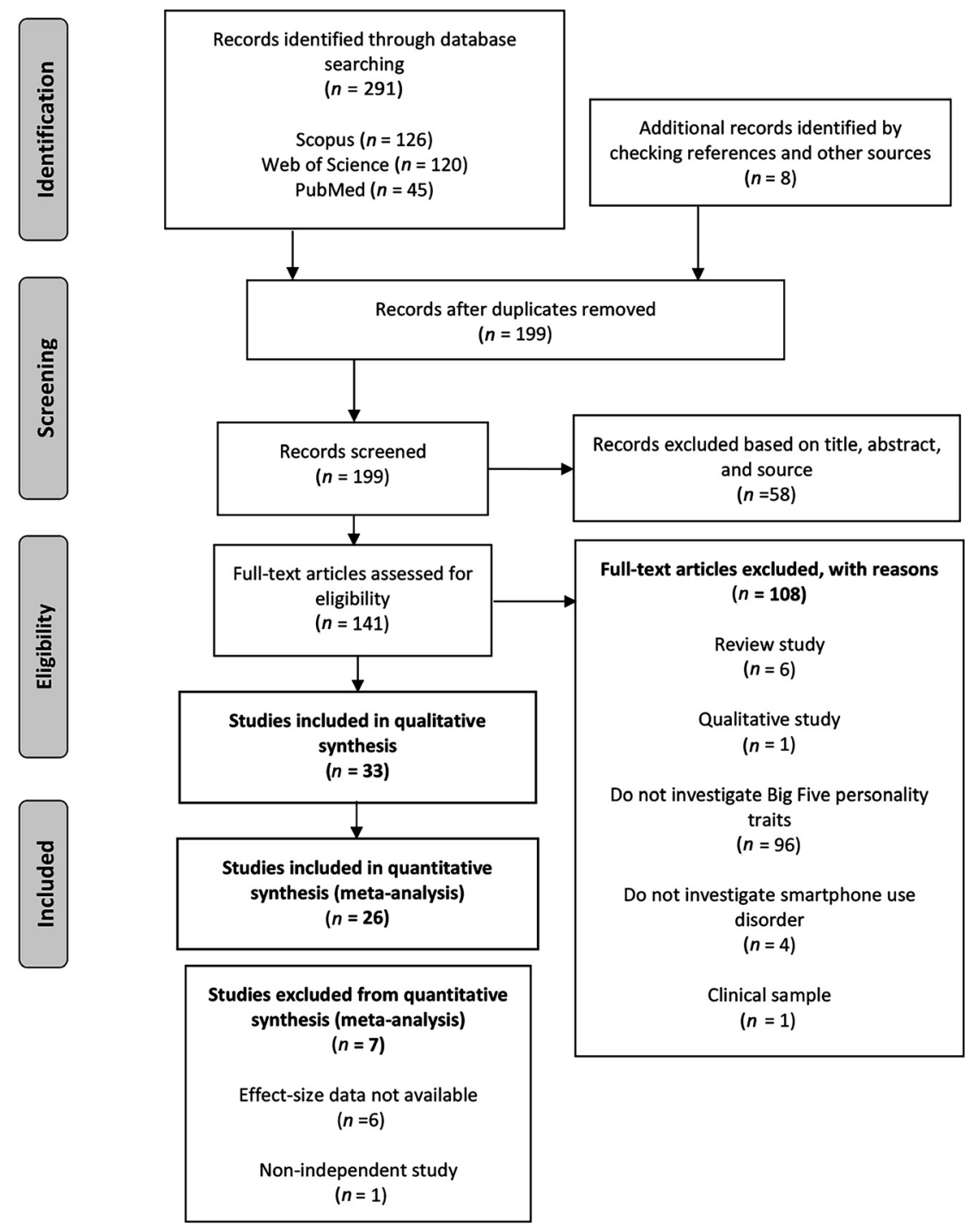

Fig. 1. Flow diagram of study selection

\section{Research coding}

Selected studies were coded for relevant characteristics, including demographic variables, sources of bias, and information about self-report assessment and time of publication. Coding of studies was performed by two independent authors, which showed full agreement on all the coded characteristics. The coded characteristics are shown below.

Sample characteristics. Each study was coded for number of participants recruited, gender distribution (\% of female participants), age (mean and standard deviation), the reference population, and country in which the study was performed.

Sources of bias. Following PRISMA guidelines, selected studies were assessed for possible sources of bias. For the purpose of the present study, we followed recent recommendations (Agarwald, Guyatt, \& Busse, 2019) and inspected studies for information on the following domains: sampling strategy used to recruit participants (random vs. convenience sampling), availability of information about response rate, missing data, and validity and reliability of survey instruments. Validity of survey instruments was ascertained if assessment was performed using a previously validated instrument, while reliability was evaluated based on Cronbach's $\alpha$.

Length of personality assessment. A key factor that may influence the strength of associations between personality and SmUD severity is related to the length of the personality assessment employed by studies (i.e., the number of administered items). Selected studies employed a variety of questionnaires assessing Big Five personality traits: the NEO Personality Inventory (NEO PI-R) (Costa \& McCrae, 1992), NEO-Five Factor Inventory (NEO-FFI) (Costa \& McCrae, 1992), Ten-Item Personality Inventory (TIPI) (Gosling, Rentfrow, \& Swann, 2003), International Personality Item Pool scales (IPIP NEO-PI-R) (Goldberg, 1999), IPIP-20 (Donnellan, Oswald, Baird, \& Lucas, 2006), Mini Markers Questionnaire (Saucier, 1994), Big Five Inventory (BFI) (John, Naumann, \& Soto, 2008), the BFI - 10 (BFI-10) 
(Rammstedt \& John, 2007), BFI-S (Lang, John, Lüdtke, Schupp, \& Wagner, 2011), and a shortened version of the Trait Self-Description Inventory (TSDI) (Christal, 1994). These questionnaires vary significantly in their length, ranging from 300 items (e.g., the IPIP NEO-PI-R) to just 10 items (e.g., the TIPI and BFI-10). In the present study, for the purpose of comparing questionnaire length, we coded studies distinguishing between those using brief assessments (10 items) versus longer assessments (>10 items).

Time of publication. Since the first introduction of smartphones to the market, significant changes and improvements have been introduced making the smartphone more and more attractive, possibly affecting the way personality traits relate to the risk of developing SmUD. Here, we also tested for the impact of time of publication on the studied relationships (i.e., correlations between personality traits and SmUD). For the purpose of the present study, in order to investigate potential time-related differences in effect sizes, we coded studies based on their year of publication.

\section{Strategy of analyses}

For each association between Big Five personality traits and SmUD examined in the selected studies, an effect size was collected. More specifically, we retrieved the correlation coefficients (Pearson or Spearman) expressing the relationship between SmUD and each Big Five personality trait. For the purpose of computing the meta-analytic correlations, we chose not to transform correlations into Fisher's $z$ scores because this transformation leads to an overestimation that exceeds the underestimation typically observed when using untransformed correlations (Hunter, Schmidt, \& Jackson, 1982). When studies did not report correlations, we contacted the first and/or corresponding authors of the study to obtain any missing information. Missing correlations were obtained for nine studies $(n=9)$.

We conducted a separate meta-analysis for each Big Five trait. Meta-analyses were performed using a random-effects model as the true effect size was likely to vary across studies due to significant heterogeneity in the characteristics of questionnaires used to assess personality and SmUD, cultural context, and sample characteristics. Grubb's test was used to identify outliers. Heterogeneity of effect sizes was determined using the following statistics: (1) $Q$ test of heterogeneity, (2) $T^{2}$ estimate of true between-study variance, and (3) the $I^{2}$ statistic of proportion of true variation in observed effects.

Publication bias was investigated by inspecting the funnel plot of an included study's effect size against its standard error. For the purpose of detecting asymmetry, estimation was performed on transformed effect sizes (Fisher's $Z$ transformation). Symmetry of the funnel plot was determined by using the rank correlation test by Begg and Mazumdar (1994), and Egger's intercept test (Sterne \& Egger, 2001). Classic fail-safe $N$ was used to determine the "file drawer" effect, which is the number of missing studies that would nullify a significant meta-analytic correlation.
Finally, Duval and Tweedie's trim and fill procedure (Duval \& Tweedie, 2000) was used to determine the existence of potentially missing studies on the left and right side of the funnel plot based on the distribution of effect-sizes. If missing studies were found, imputation was performed in order to compute an unbiased estimate of effect.

Then, effect of dichotomous or continuous moderators (i.e., gender, sample age, length of personality questionnaires, year of publication of the studies) was measured via randomeffects univariate meta-regressions using restricted maximum-likelihood estimation. A priori evaluation of power for moderator tests was performed based on existing recommendations (Hedges \& Pigott, 2004). For the purpose of analysis, length of questionnaire was operationalized using a dichotomous variable coded 0 for brief questionnaires including $\leq 10$ items, and 1 for questionnaires including more than 10 items. Year of publication was coded as a continuous variable ranging from 2008 to 2020. Genderrelated effects were examined using a continuous indicator representing the percentage of female participants in each sample. In coding age, we created a categorical variable distinguishing between studies performed on samples including mostly adolescent and young adult participants aged $\leq 26$, and samples including also a non-negligible group of older adults. Samples for which mean age +2 SD was $\leq 26$, were coded as 0 , while remaining studies were coded as 1 . If studies did not report information about mean age, we looked at the percentage of individuals in each age group. For all moderator effects, we report the unstandardized regression coefficients and relative standard errors, $R^{2}$ representing the percentage of variance explained, and information on heterogeneity statistics. For the purpose of investigating effects related to differences between countries, we grouped studies distinguishing studies analyzing samples from English-speaking countries (i.e., Australia, USA, and United Kingdom), mainland Europe (i.e., Austria, France, Germany, Italy, Norway, Romania, and Spain), middle-east (Israel, Turkey) and far-east (i.e., South Korea, Japan). Significance of between-group differences was established by computing the Q statistics, as well as non-overlapping 95\% confidence intervals. In order to conduct moderator analyses, and to acquire acceptably robust coefficient estimates, we followed the suggestion by $\mathrm{Fu}$ and colleagues and examined the effect of moderators only if at least 4 studies per group were available (Fu et al., 2011). All analyses were performed using the Comprehensive Meta-Analysis software, version 3 (Borenstein, Hedges, Higgins, \& Rothstein, 2005).

\section{RESULTS}

\section{Ovenview of included studies}

In total, we identified 33 papers investigating data including information about SmUD and Big Five personality scores. After exclusion of six papers for which no information about zero-order correlations could be retrieved (Delevi \& Weisskirch, 2013; Lee, 2015; Mosalanejad, Nikbakht, 
Abdollahifrad, \& Kalani, 2019; Panda \& Jain, 2018; Pearson \& Hussain, 2015; Prasad et al., 2018), 27 papers remained. After inspection of studies for non-independence, we found $n=2$ non-independent studies (Trub \& Barbot, 2016, 2020). Samples from this study were largely overlapping, and recruited participants completing the same personality and SmUD measures. To resolve this issue, we selected the study examining the larger sample (Trub \& Barbot, 2020) for inclusion in the meta-analysis, while the other study (Trub \& Barbot, 2016) was not included. Additionally, we found two papers (Smetaniuk, 2014; Trub \& Barbot, 2020) reporting more than one correlation representing the association between personality and SmUD. More specifically, Smetaniuk (2014) explored the associations between Big Five personality traits and both the Mobile Phone Problem Use Scale (Bianchi \& Phillips, 2005) and the Adapted Cell Phone Addiction Test (ACPAT) (Smetaniuk, 2014). Trub and Barbot (2020) explored the association between personality scores and three subscales of the Problematic Mobile Phone Use Scale (Güzeller \& Coşguner, 2012), namely, Negative Effect, Withdrawal/Tolerance, and Compulsion/Persistence, but did not provide information about correlations with the total score. In both these cases, because correlations were performed on the same sample using scores referring to the same broad construct (i.e., SmUD), but either different instruments or set of items were used to compute the scores, we retained all available information in the analyses by averaging effect sizes computed on the same sample.

Eventually, we ended up with 26 independent studies, including 130 distinct effect sizes. Sample characteristics of selected studies are reported in Table 1. Mean sample size of included studies was 441.79 ( $\mathrm{SD}=240.24)$, ranging from 132 (Ezoe et al., 2009) to 982 (Trub \& Barbot, 2020) participants. The majority of studies were performed on convenience samples $(n=23)$, and only a minority reported use of random sampling in recruiting participants $(n=3)$. Only one study reported information about response rate, and the majority of studies $(n=16)$ failed to provide information about handling of missing data.

Overall, recruited samples showed significant gender imbalance, with $n=17$ studies reporting samples including $\geq 60 \%$ female participants, $n=2$ reporting samples including $\geq 60 \%$ male participants, and only $n=7$ studies reporting balanced samples (from $46.41 \%$ to $50.20 \%$ of females). Mean age of samples ranged from 14.64 (GarcíaOliva \& Piqueras, 2016) to 41.12 (Hwang \& Jeong, 2015), with a mean value of 23.32 years $(\mathrm{SD}=5.59)$ across studies. A minority of studies $(n=4$, see Table 1$)$ did not include information about mean age, but only reported frequencies for different age groups, hence, information from these studies are not included in the calculation above. The majority of studies were performed on samples of either adolescent or university students $(n=15)$, while a relatively smaller group of studies $(n=11)$ were performed on either adult parents $(n=1)$, or general population samples $(n=$ $10)$. Included studies were diverse with regard to country of residence of recruited participants: The majority of studies were performed on samples collected in European countries
( $n=12$, Austria, Germany, Italy, Norway, Romania, Spain, and United Kingdom); samples from remaining studies were recruited in the United States $(n=4)$, Australia $(n=2)$, Israel $(n=2)$, South Korea $(n=2)$, Japan $(n=2)$, Turkey $(n=1)$, or on international, English-speaking samples $(n=1)$.

Characteristics of self-report instruments used in selected studies are reported in Table 2. All studies used previously validated instruments to assess Big Five traits, including either original or revised versions of the TIPI $(n=7)$, NEOFFI $(n=6)$, IPIP scales $(n=4)$, BFI-44 $(n=2)$, BFI-10 ( $n=3$; or an alternative short BFI version, the BFI-S, $n=1)$, the NEO-PI-R $(n=1)$, a short version of the TSDI $(n=1)$, and the Mini Markers $(n=1)$ questionnaire. Reliability of personality assessments was reported by $n=19$ studies, while $n=7$ studies failed to report this information. In all studies, reliability was comparable to the one reported in their relative validation studies. As expected, reliability values for short assessments (questionnaire length $\leq 10$ items) was generally lower than those reported for longer instruments.

Regarding the questionnaires used to assess SmUD, $n=5$ studies reported using custom questionnaires (i.e., questionnaires with items were specifically developed for the study, or adapted from other questionnaires). Remaining studies used previously validated questionnaires, namely the Smartphone Addiction Scale $(n=3)$ (SAS; Kwon, Lee, et al., 2013), Smartphone Addiction Scale - Short Version $(n=3)$ (SASSV; Kwon, Kim, et al., 2013), Mobile Phone Problematic Use Scale $(n=5)$ (MPPUS; Bianchi \& Phillips, 2005), Smartphone Addiction Symptoms Scale $(n=2)$ (SAPS; Bian \& Leung, 2015), the Adapted Cell Phone Addiction Test $(n=1)$ (ACPAT; Smetaniuk, 2014), Questionnaire of Experiences Related to Mobile Phones ( $n=1$; also referred to as Cuestionario de Experiencias Relacionadas con el Móvil, or CERM, in Spanish) (Beranuy, Chamarro, Graner, \& Carbonell, 2009), Mobile Phone Addiction Index $(n=1)$ (MPAI, Leung, 2007), Problematic Mobile Phone Use Scale $(n=1)$ (PMPU; Güzeller \& Coşguner, 2012), Smart-Phone Addiction Inventory $(n=1)$ (SPAI; Lin et al., 2014), Mobile Phone Dependence Questionnaire $(n=1)$ (MPDQ; Toda, Monden, Kubo, \& Morimoto, 2004), Mobile Phone Usage Addiction Scale $(n=1)$ (MPUAS; Karadağ et al., 2015), revised Problematic Mobile Phone Use Questionnaire $(n=1)$ (PMPU-Q; Kuss, Harkin, Kanjo, \& Billieux, 2018), and the Self-Assessment Scale $(n=1)$ (S-Scale, National Information Society Agency, 2011). Except for $n=2$ studies that failed to include reliability coefficients, reported reliability of SmUD assessments was acceptable for all studies (Cronbach' $\alpha$ ranging from 0.66 to 0.96 ).

\section{Meta-analytic computations}

Mean effect size. Before computing meta-analytical computations, Grubb's test was applied to effect size data for each personality trait. Grubb's test failed to identify any outliers, resulting in no effect sizes being excluded from subsequent analyses. 
Table 1. Sample characteristics of studies included in the meta-analysis

\begin{tabular}{|c|c|c|c|c|c|c|c|}
\hline \multirow[b]{2}{*}{ Study name } & \multicolumn{7}{|c|}{ Sample characteristics } \\
\hline & $N$ & $\begin{array}{l}\text { Mean age } \\
\text { (SD) }\end{array}$ & Reference population & $\begin{array}{c}\text { Female } \\
(\%)\end{array}$ & Country & $\begin{array}{l}\text { Sampling } \\
\text { strategy }\end{array}$ & $\begin{array}{l}\% \text { of valid } \\
\text { data }\end{array}$ \\
\hline Andreassen et al. (2013) & 218 & $20.7(3.0)^{\mathrm{b}}$ & University students & 79.16 & Norway & Convenience & - \\
\hline Augner \& Hacker (2012) & 196 & $20.1(3.2)^{\mathrm{b}}$ & University students & 76.53 & Austria & Convenience & - \\
\hline Cho, Kim, and Park (2017) & 400 & $20-49^{\mathrm{a}}$ & General population & 48.50 & South Korea & Convenience & - \\
\hline $\begin{array}{l}\text { Cocoradă, Maican, Cazan, } \\
\text { and Maican (2018) }\end{array}$ & 717 & $19.8(-)^{\mathrm{b}}$ & $\begin{array}{l}\text { Adolescent and university } \\
\text { students }\end{array}$ & 65.00 & Romania & Convenience & - \\
\hline $\begin{array}{l}\text { De Pasquale, Sciacca, Conti, } \\
\text { Dinaro, and Di Nuovo } \\
(2019)\end{array}$ & 400 & $21.6(1.4)^{\mathrm{b}}$ & University students & 61.00 & Italy & Convenience & $93 \%$ \\
\hline $\begin{array}{l}\text { Demirhan, Randler, and } \\
\text { Horzum (2016) }\end{array}$ & 902 & $20.4(1.9)^{\mathrm{b}}$ & University students & 73.00 & Turkey & Convenience & - \\
\hline $\begin{array}{l}\text { Ehrenberg, Juckes, White, \& } \\
\text { Walsh (2008) }\end{array}$ & 200 & $19.1(1.8)^{\mathrm{b}}$ & University students & 73.00 & Australia & Convenience & - \\
\hline Ezoe et al. (2009) & 132 & $24.5(5.7)$ & University students & 100.00 & Japan & Convenience & - \\
\hline $\begin{array}{l}\text { García-Oliva \& Piqueras } \\
\text { (2016) }\end{array}$ & 304 & $14.6(1.7)^{\mathrm{b}}$ & Adolescents & 48.60 & Spain & Convenience & - \\
\hline $\begin{array}{l}\text { Guazzini, Duradoni, Capelli, } \\
\text { and Meringolo (2019) }\end{array}$ & 394 & $24.2(9.14)$ & General population & 84.80 & Italy & Convenience & $92 \%$ \\
\hline $\begin{array}{l}\text { Herrero, Urueña, Torres, and } \\
\text { Hidalgo (2019a) }\end{array}$ & 526 & $15+^{\mathrm{a}}$ & General population & 48.10 & Spain & $\begin{array}{l}\text { Random } \\
\text { sample }\end{array}$ & - \\
\hline $\begin{array}{l}\text { Herrero, Urueña, Torres, and } \\
\text { Hidalgo (2019b) }\end{array}$ & 416 & $15+^{\mathrm{a}}$ & General population & 47.80 & Spain & $\begin{array}{l}\text { Random } \\
\text { sample }\end{array}$ & $63 \%$ \\
\hline Horwood \& Anglim (2018) & 398 & $24.4(7.1)$ & University students & 79.00 & Australia & Convenience & $79 \%$ \\
\hline $\begin{array}{l}\text { Hussain, Griffiths, and } \\
\text { Sheffield (2017) }\end{array}$ & 640 & $24.9(8.5)$ & General population & 65.60 & $\begin{array}{l}\text { United } \\
\text { Kingdom }\end{array}$ & Convenience & $74 \%$ \\
\hline Hwang \& Jeong (2015) & 460 & $41.1(3.6)$ & Adult parents & 50.20 & South Korea & $\begin{array}{l}\text { Random } \\
\text { sample }\end{array}$ & $77 \%$ \\
\hline Kita \& Luria (2018) & 221 & $19.3(1.7)^{\mathrm{b}}$ & Young drivers & 35.29 & Israel & Convenience & $92 \%$ \\
\hline Kruger \& Djerf (2017) & 766 & $19.0(1.0)^{\mathrm{b}}$ & University students & 50.13 & USA & Convenience & - \\
\hline Lachmann et al. (2019) & 572 & $23.6(5.9)$ & University students & 72.03 & Germany & Convenience & - \\
\hline Mitchell \& Hussain (2018) & 147 & $31.0(13.0)$ & General population & 69.40 & $\begin{array}{l}\text { United } \\
\text { Kingdom }\end{array}$ & Convenience & $83 \%$ \\
\hline $\begin{array}{l}\text { Peterka-Bonetta, } \\
\text { Sindermann, Elhai, and } \\
\text { Montag (2019) }\end{array}$ & 773 & $23.1(7.3)$ & General population & 60.80 & $\begin{array}{l}\text { English- } \\
\text { speaking }\end{array}$ & Convenience & - \\
\hline $\begin{array}{l}\text { Pivetta, Harkin, Billieux, } \\
\text { Kanjo, and Kuss (2019) }\end{array}$ & 508 & $25.5(9.9)$ & General population & 78.30 & $\begin{array}{l}\text { United } \\
\text { Kingdom }\end{array}$ & Convenience & - \\
\hline Smetaniuk (2014) & 362 & $32(-)$ & General population & 46.41 & USA & Convenience & $83 \%$ \\
\hline Takao (2014) & 504 & $20.1(1.4)^{\mathrm{b}}$ & University students & 21.43 & Japan & Convenience & $83 \%$ \\
\hline Trub \& Barbot (2020) & 982 & $24.5(3.4)$ & Young drivers & 60.00 & USA & Convenience & - \\
\hline $\begin{array}{l}\text { Volungis, Kalpidou, Popores, } \\
\text { and Joyce (2019) }\end{array}$ & 150 & $19.3(-)^{\mathrm{b}}$ & University students & 83.20 & USA & Convenience & - \\
\hline $\begin{array}{l}\text { Zhitomirsky-Geffet \& Blau } \\
\text { (2016) }\end{array}$ & 209 & $13-68^{\mathrm{a}}$ & General population & 63.00 & Israel & Convenience & $97 \%$ \\
\hline
\end{tabular}

a Studies did not reported mean age values: range is reported.

${ }^{\mathrm{b}}$ Studies focusing on adolescents and young adults aged $\leq 26$.

Next, in order to establish the magnitude of associations between SmUD severity and each of the Big Five personality traits, we conducted one separate meta-analysis for each individual personality trait, analyzing effect size data collected from different numbers of studies, depending on the specific trait (Openness: $n=23$; Conscientiousness: $n=$ 23; Extraversion: $n=26$; Agreeableness: $n=22$; Neuroticism: $n=25$ ). Forest plots of effect sizes included in the meta-analyses are presented in Figs. 2-6. The estimated meta-analytic correlations are presented in Table 3, alongside Q tests for heterogeneity, $\mathrm{T}^{2}$, and $I^{2}$ statistics. Overall, Neuroticism showed the strongest positive meta-analytic correlation with SmUD severity $(r=0.25[0.21,0.29])$, while Conscientiousness showed the strongest negative meta-analytic correlation $(r=-0.16[-0.20,-0.16])$. Meta-analytic correlations for Openness $(r=-0.08[-0.12,-0.04])$ and 
Table 2. Characteristics of self-report instruments used in studies included in the meta-analysis

\begin{tabular}{|c|c|c|c|c|c|}
\hline \multirow[b]{2}{*}{ Study name } & \multicolumn{3}{|c|}{ Big Five personality } & \multicolumn{2}{|c|}{ Smartphone use disorder } \\
\hline & $\begin{array}{l}\text { Questionnaire, } \\
\text { \# of items }\end{array}$ & Assessed traits & Reliability $(\alpha)$ & Questionnaire & $\begin{array}{l}\text { Reliability } \\
\qquad(\alpha)\end{array}$ \\
\hline Andreassen et al. (2013) & NEO-FFI-R, 60 & $\mathrm{O}, \mathrm{C}, \mathrm{E}, \mathrm{A}, \mathrm{N}$ & $0.77-0.85$ & MPAI & 0.84 \\
\hline Augner \& Hacker (2012) & TIPI, 10 & $\mathrm{O}, \mathrm{C}, \mathrm{E}, \mathrm{A}, \mathrm{N}$ & Not reported & Custom questionnaire & 0.90 \\
\hline Cho et al. (2017) & Adapted NEO-PI-R, 25 & $\mathrm{O}, \mathrm{C}, \mathrm{E}, \mathrm{A}, \mathrm{N}$ & $0.65-0.86$ & S-Scale & 0.77 \\
\hline Cocoradă et al. (2018) & IPIP, 50 & $\mathrm{O}, \mathrm{C}, \mathrm{E}, \mathrm{A}, \mathrm{N}$ & $0.71-0.81$ & SAS-SV & 0.86 \\
\hline De Pasquale et al. (2019) & TIPI, 10 & $\mathrm{O}, \mathrm{C}, \mathrm{E}, \mathrm{A}, \mathrm{N}$ & $0.40-0.73$ & SAS-SV & 0.85 \\
\hline Demirhan et al. (2016) & TIPI, 10 & $\mathrm{O}, \mathrm{C}, \mathrm{E}, \mathrm{A}, \mathrm{N}$ & $0.70-0.75$ & MPPUS & 0.90 \\
\hline Ehrenberg et al. (2008) & NEO-FFI, 60 & $\mathrm{O}, \mathrm{C}, \mathrm{E}, \mathrm{A}, \mathrm{N}$ & $0.68-0.84$ & Custom questionnaire & 0.69 \\
\hline Ezoe et al. (2009) & NEO-FFI, 60 & E, $N$ & Not reported & MPDQ & 0.86 \\
\hline García-Oliva \& Piqueras (2016) & TIPI, 10 & $\mathrm{O}, \mathrm{C}, \mathrm{E}, \mathrm{A}, \mathrm{N}$ & Not reported & CERM & 0.66 \\
\hline Guazzini et al. (2019) & TIPI, 10 & $\mathrm{O}, \mathrm{C}, \mathrm{E}, \mathrm{A}, \mathrm{N}$ & Not reported & MPUAS & $0.78-0.86$ \\
\hline Herrero et al. (2019a) & BFI, 10 & $\mathrm{O}, \mathrm{C}, \mathrm{E}, \mathrm{A}, \mathrm{N}$ & Not reported & SAPS & Not reported \\
\hline Herrero et al. (2019b) & BFI, 10 & $\mathrm{O}, \mathrm{C}, \mathrm{E}, \mathrm{A}, \mathrm{N}$ & $\geq 0.65$ & SAPS & Not reported \\
\hline Horwood \& Anglim (2018) & IPIP, 300 & $\mathrm{O}, \mathrm{C}, \mathrm{E}, \mathrm{A}, \mathrm{N}$ & $0.89-0.96$ & MPPUS & 0.91 \\
\hline Hussain et al. (2017) & TIPI, 10 & $\mathrm{O}, \mathrm{C}, \mathrm{E}, \mathrm{A}, \mathrm{N}$ & $0.29-0.69$ & Custom questionnaire & 0.86 \\
\hline Hwang \& Jeong (2015) & BFI-S, 15 & $\mathrm{O}, \mathrm{C}, \mathrm{E}, \mathrm{A}, \mathrm{N}$ & $0.59-0.91$ & Custom questionnaire & 0.90 \\
\hline Kita \& Luria (2018) & IPIP, 20 & $\mathrm{O}, \mathrm{C}, \mathrm{E}, \mathrm{A}, \mathrm{N}$ & $0.69-0.79$ & SAS-SV & 0.79 \\
\hline Kruger \& Djerf (2017) & TIPI, 10 & $\mathrm{O}, \mathrm{C}, \mathrm{E}, \mathrm{A}, \mathrm{N}$ & Not reported & MPPUS & 0.82 \\
\hline Lachmann et al. (2019) & NEO-FFI, 60 & $\mathrm{O}, \mathrm{C}, \mathrm{E}, \mathrm{A}, \mathrm{N}$ & $0.75-0.86$ & SAS & 0.98 \\
\hline Mitchell \& Hussain (2018) & Mini Markers, 40 & $\mathrm{E}$ & 0.86 & Custom questionnaire & 0.86 \\
\hline Peterka-Bonetta et al. (2019) & TSDI, 42 & $\mathrm{O}, \mathrm{C}, \mathrm{E}, \mathrm{A}, \mathrm{N}$ & $0.79-0.87$ & SPAI & 0.95 \\
\hline Pivetta et al. (2019) & BFI, 10 & $\mathrm{C}, \mathrm{E}, \mathrm{N}$ & $0.42-0.45$ & PMPU-Q & 0.86 \\
\hline Smetaniuk (2014) & IPIP, 50 & $\mathrm{E}, \mathrm{N}$ & $0.72-0.93$ & ACPAT, MPPUS & $0.96-0.96$ \\
\hline Takao (2014) & NEO FFI, 60 & $\mathrm{O}, \mathrm{C}, \mathrm{E}, \mathrm{A}, \mathrm{N}$ & Not reported & MPPUS & 0.9 \\
\hline Trub \& Barbot (2020) & BFI, 44 & $\mathrm{O}, \mathrm{C}, \mathrm{E}, \mathrm{A}, \mathrm{N}$ & $0.81-0.87$ & PMPU & $0.80-0.87$ \\
\hline Volungis et al. (2019) & NEO FFI, 60 & $\mathrm{O}, \mathrm{C}, \mathrm{E}, \mathrm{A}, \mathrm{N}$ & 0.89 & SAS & $0.78-0.86$ \\
\hline Zhitomirsky-Geffet \& Blau (2016) & BFI, 44 & $\mathrm{O}, \mathrm{C}, \mathrm{E}, \mathrm{A}, \mathrm{N}$ & $0.68-0.88$ & SAS & 0.97 \\
\hline
\end{tabular}

Note: O, Openness; C, Conscientiousness; E, Extraversion; A, Agreeableness; N, Neuroticism.

\section{Openness}

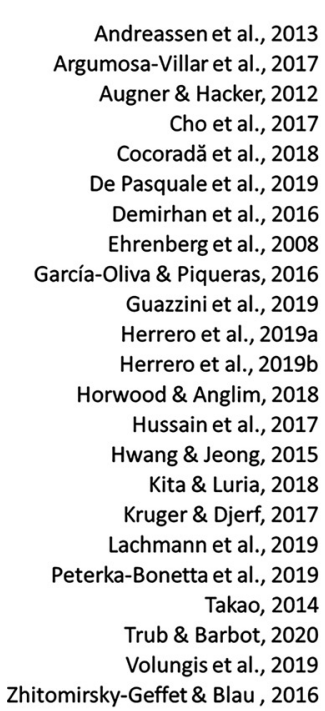

Central tendency
$-.19[-.31,-.06]$
$-.15[-.27,-.02]$
$-.02[-.16, .13]$
$.00[-.10, .10]$
$-.15[-.22,-.08]$
$-.06[-.16, .03]$
$-.01[-.08, .06]$
$-.05[-.19, .09]$
$-.06[-.17, .05]$
$0.00[-.10, .10]$
$-.15[-.23,-.07]$
$-.10[-.19,-.00]$
$-.15[-.25,-.05]$
$-.15[-.22,-.07]$
$.16[.07, .25]$
$-.07[-.20, .06]$
$-.02[-.09, .05]$
$-.14[-.22,-.06]$
$-.13[-.20,-.06]$
$-.13[-.21,-.04]$
$0.00[-.06, .06]$
$-.22[-.37,-.06]$
$-.24[-.36,-.11]$
$-.08[-.12,-.04]$

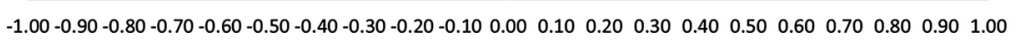

Fig. 2. Forest plot of effect sizes for the association between smartphone use disorder severity and Openness 


\section{Conscientiousness}

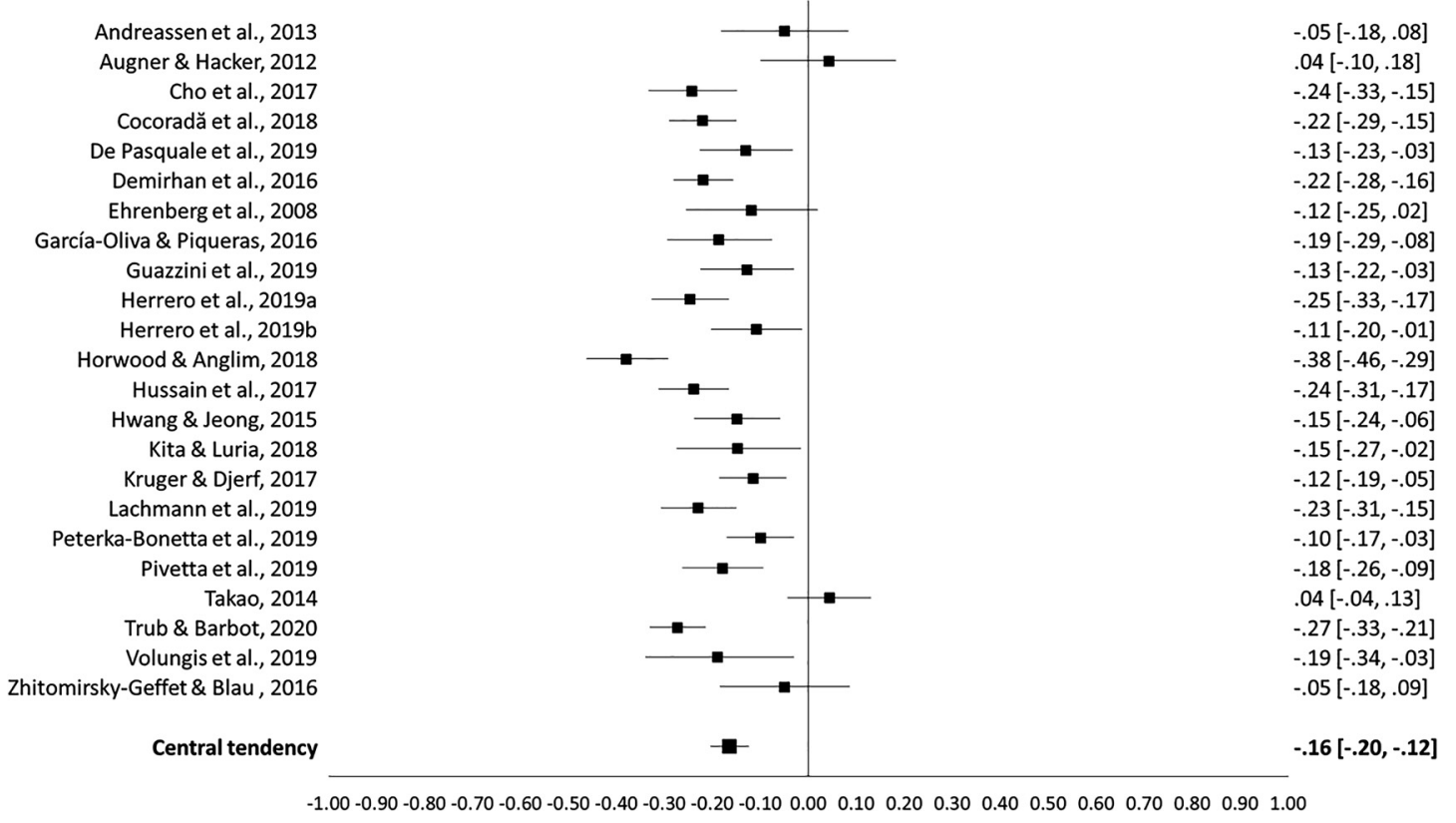

Fig. 3. Forest plot for effect sizes of the association between smartphone use disorder severity and Conscientiousness

\section{Extraversion}
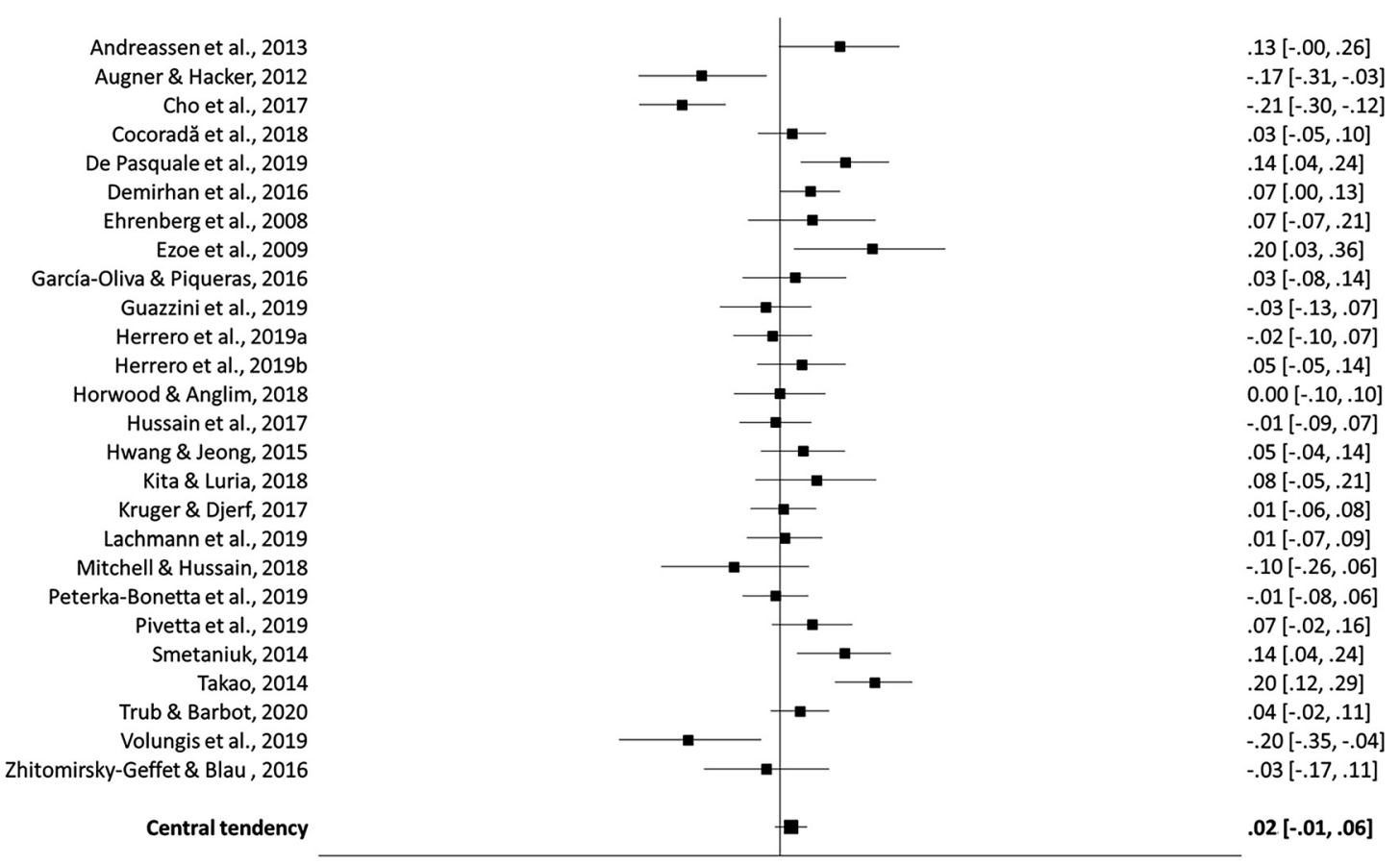

$-1.00-0.90-0.80-0.70-0.60-0.50-0.40-0.30-0.20-0.100 .000 .100 .200 .300 .40 \quad 0.500 .600 .700 .800 .90 \quad 1.00$

Fig. 4. Forest plot for effect sizes of the association between smartphone use disorder severity and Extraversion

Agreeableness $(r=-0.06[-0.09,-0.02])$ were negligible in size, but significantly different from zero. In turn, Extraversion showed a non-significant meta-analytic correlation $(r=0.02[-0.01,0.06])$. Results of Q tests for heterogeneity were significant for each trait. However, for all traits, $\mathrm{T}^{2}$ did not exceed 0.01, indicating low between-study heterogeneity. Additionally, for all traits, observed dispersion of effect sizes was mostly due to true heterogeneity $\left(I^{2} \geq 68.16\right)$. 


\section{Agreeableness}
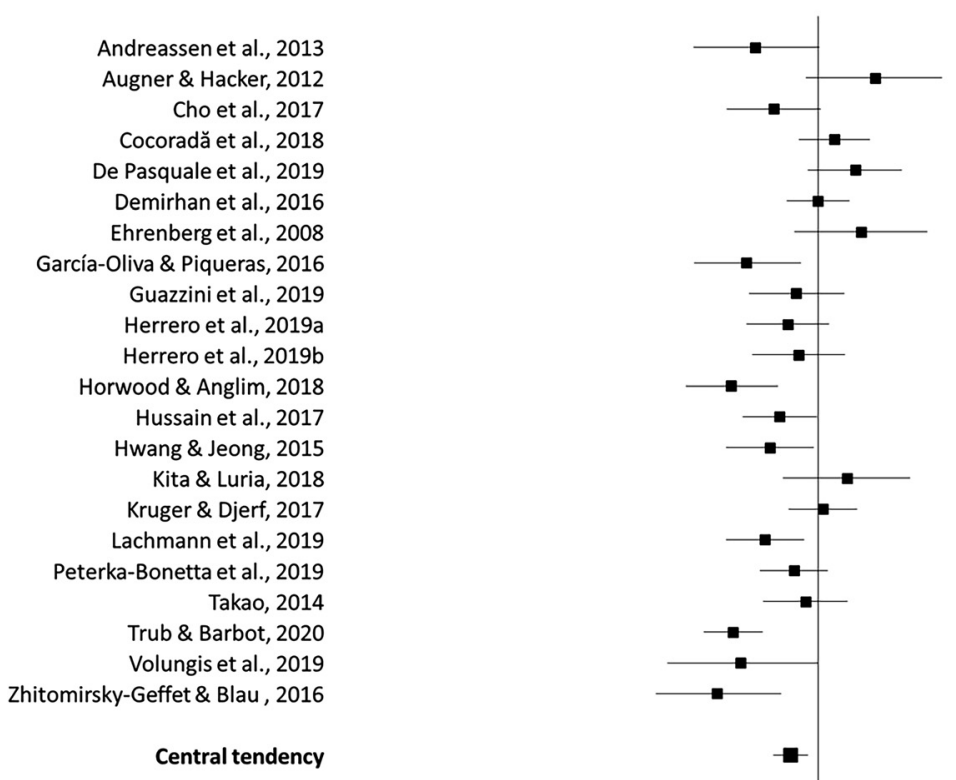

$-.13[-.26, .01]$

$.12[-.03, .26]$

$-.09[-.19, .01]$

$.03[-.04, .11]$

$.08[-.02, .17]$

$.00[-.07, .07]$

$.09[-.05, .23]$

$-.15[-.26,-.04]$

$-.05[-.14, .05]$

$-.06[-.15, .02]$

$-.04[-.14, .06]$

$-.18[-.27,-.08]$

$-.08[-.16,-.00]$

$-.10[-.19,-.01]$

$.06[-.07, .19]$

$.01[-.06, .08]$

$-.11[-.19,-.03]$

$-.05[-.12, .02]$

$-.03[-.11, .06]$

$-.18[-.24,-.12]$

$-.16[-.31, .00]$

$-.21[-.34,-.08]$

Central tendency

$-.06[-.09,-.02]$

$-1.00-0.90-0.80-0.70-0.60-0.50-0.40-0.30-0.20-0.100 .000 .100 .200 .300 .40 \quad 0.500 .600 .700 .800 .90 \quad 1.00$

Fig. 5. Forest plot for effect sizes of the association between smartphone use disorder severity and Agreeableness

\section{Neuroticism}

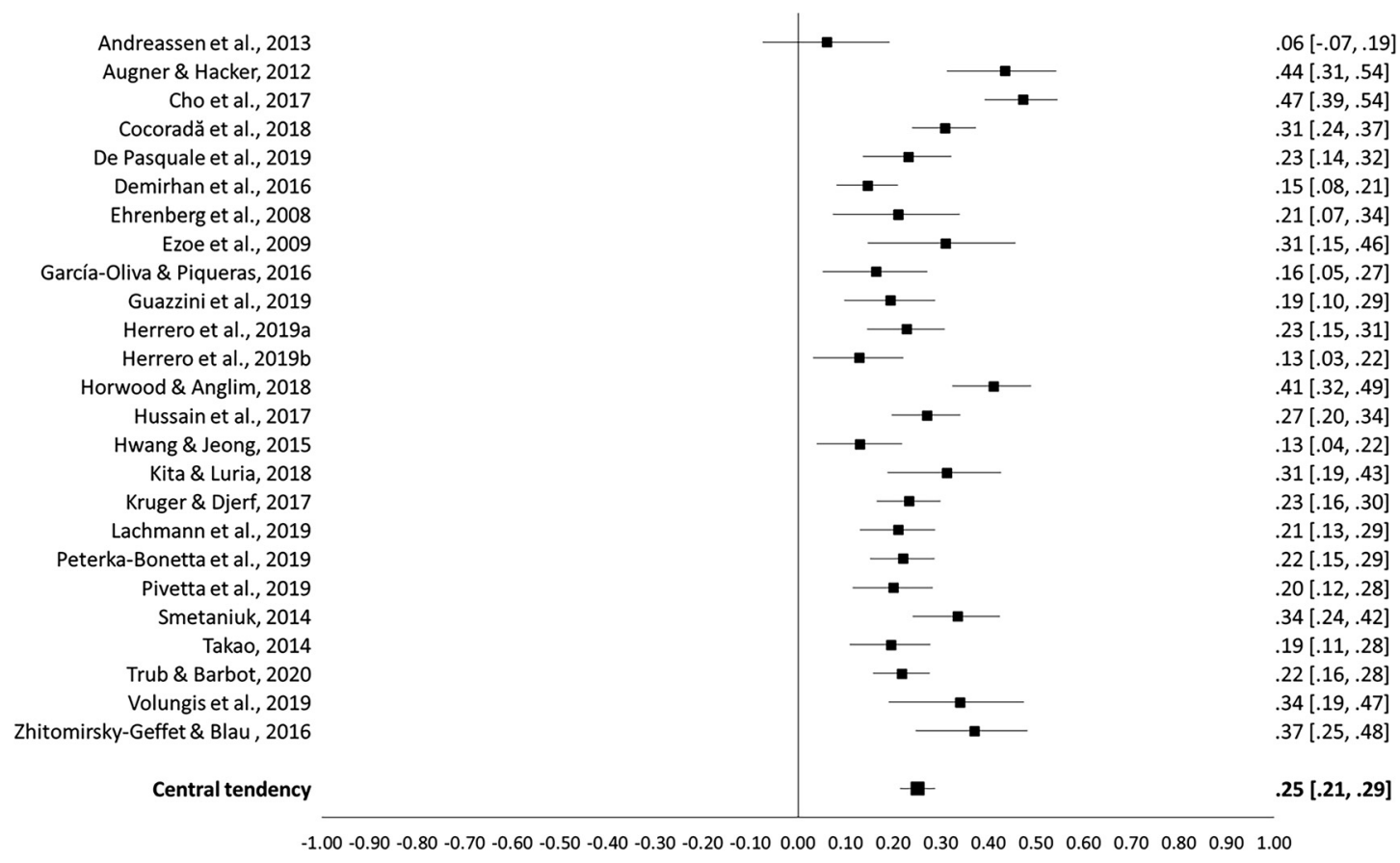

Fig. 6. Forest plot for effect sizes of the association between smartphone use disorder severity and Neuroticism

Publication bias. We inspected the funnel plots of standard error versus the correlation (given as Fisher's z) (see Figs. S1-S5 in the Supplementary Material). For each Big Five trait, the funnel plot was symmetric, suggesting lack of publication bias. For each trait, non-significant Begg and
Mazumdar tests (Openness: $P=0.25$, Conscientiousness: $P=0.06$; Extraversion: $P=0.35$; Agreeableness: $P=0.75$; Neuroticism: $P=0.21$ ) and Egger's tests (Openness: $P=$ 0.17, Conscientiousness: $P=0.06$; Extraversion: $P=0.28$; Agreeableness: $P=0.45$; Neuroticism: $P=0.08$ ) further 
Table 3. Meta-analytic correlations and heterogeneity statistics between smartphone use disorder and Big Five personality traits

\begin{tabular}{lcccrrr}
\hline Trait & Point estimate $[95 \% \mathrm{CI}]$ & $Z$ & $Q(\mathrm{df})$ & $I^{2}$ & $T^{2}$ & $T$ \\
\hline Openness & $-0.08[-0.12,-0.04]$ & $-4.28^{* *}$ & $74.45(21)^{* *}$ & 71.79 & 0.01 & 0.07 \\
Conscientiousness & $-0.16[-0.20,-0.12]$ & $-8.03^{* *}$ & $95.70(22)^{* *}$ & 77.01 & 0.01 & 0.09 \\
Extraversion & $0.02[-0.01,0.06]$ & 1.34 & $83.19(25)^{* *}$ & 69.95 & 0.01 & 0.07 \\
Agreeableness & $-0.06[-0.09,-0.02]$ & $3.08^{*}$ & $67.34(21)^{* *}$ & 68.16 & $<0.01$ & 0.07 \\
Neuroticism & $0.25[0.21,0.29]$ & $9.96^{* *}$ & $102.58(24)^{* *}$ & 76.60 & 0.01 & 0.09 \\
\hline
\end{tabular}

Note: ${ }^{\star} P<0.01{ }^{\star *} P<0.001$.

indicated no significant evidence of asymmetry in the funnel plot, suggesting no publication bias.

Except for Extraversion, for each trait the fail-safe $N$ (Openness: $N=334$; Conscientiousness: $N=1,729$; Agreeableness: $N=154$; Neuroticism: $N=4,362$ ) value was significantly larger than the recommended rule-of-thumb limit as computed for each trait $(5 \times$ number of effect sizes +10 ; Rosenthal, 1979). For Extraversion, the estimated failsafe $N$ was 18 , below the computed rule-of-thumb limit of 140 , further supporting the non-significance of the metaanalytic correlation emerging for the trait.

Finally, we used Duval and Tweedie's trim and fill procedure to detect potentially missing studies on the left and right of the funnel plot. For all the traits, except for the Openness trait, the procedure indicated no studies were missing on the left and right side of the plot. Regarding the Openness trait, the procedure detected one study potentially missing on the right side of the plot (i.e., a study reporting a positive effect-size). However, after imputation of the missing study, the overall effect-size of association between Openness and SmUD was unchanged (Point Estimate = 0.08 ; Imputed Point Estimate $=0.08$ ), suggesting the bias to be negligible. Combined, results of these tests indicate that it is unlikely that publication bias posed a significant threat to validity of the findings reported in the current analyses.

Moderator analyses. Results of moderation analyses are shown in Table 4. Please note that based on a priori power computations assuming random-effects, high heterogeneity across studies, and $n=25$ expected studies, power for all moderator effects was expected to be below acceptable thresholds (power <0.80), except for large effects. Still, because the recruited number of studies for each association was either above or just below sample-size recommendations for detecting linear patterns in meta-regression analyses (Jenkins \& Quintana-Ascenscio, 2020), we decided to perform the analyses. Results should be seen in view of these considerations.

First, we examined possible effects related to sample characteristics, namely the distribution of gender and age in the samples. Results showed no significant moderation effects for gender. In turn, we found older age was associated with an increase in strength of the negative association between SmUD, and both the Agreeableness and Conscientiousness traits. More specifically, when examining the link between these traits and SmUD, studies performed on older

Table 4. Moderator analyses

\begin{tabular}{lcccrrrr}
\hline Effect & Trait & Coefficient & SE & $R^{2}$ & $I^{2}$ & $T^{2}$ & T \\
\hline Length of assessment & Openness & -0.03 & 0.04 & 0.00 & 72.72 & 0.01 & 0.08 \\
& Conscientiousness & -0.01 & 0.04 & 0.00 & 78.00 & 0.01 & 0.09 \\
& Extraversion & 0.01 & 0.04 & 0.00 & 71.14 & 0.01 & 0.08 \\
& Agreeableness & -0.06 & 0.04 & 0.13 & 65.45 & $<0.01$ & 0.07 \\
& Neuroticism & 0.06 & 0.04 & 0.16 & 75.45 & 0.01 & 0.09 \\
Year of publication & Openness & 0.00 & 0.01 & 0.00 & 72.82 & 0.01 & 0.08 \\
& Conscientiousness & -0.02 & 0.01 & 0.26 & 74.75 & 0.01 & 0.08 \\
& Extraversion & -0.01 & 0.01 & 0.06 & 68.78 & 0.01 & 0.08 \\
& Agreeableness & -0.01 & 0.01 & 0.00 & 66.62 & 0.01 & 0.07 \\
& Neuroticism & 0.00 & 0.01 & 0.00 & 77.55 & 0.01 & 0.10 \\
Gender & Openness & -0.08 & 0.13 & 0.00 & 72.90 & 0.01 & 0.08 \\
& Conscientiousness & -0.17 & 0.13 & 0.08 & 74.36 & 0.01 & 0.08 \\
& Extraversion & -0.12 & 0.12 & 0.02 & 69.58 & 0.01 & 0.08 \\
& Agreeableness & -0.07 & 0.12 & 0.00 & 70.02 & $<0.01$ & 0.07 \\
& Neuroticism & 0.05 & 0.13 & 0.00 & 77.55 & 0.01 & 0.10 \\
Age & Openness & 0.01 & 0.04 & 0.00 & 73.15 & 0.01 & 0.08 \\
& Conscientiousness & -0.08 & 0.04 & 0.15 & 74.64 & 0.01 & 0.08 \\
& Extraversion & -0.04 & 0.04 & 0.03 & 68.95 & 0.01 & 0.01 \\
& Agreeableness & $-0.10^{* *}$ & 0.03 & 0.61 & 49.61 & $<0.01$ & 0.04 \\
& Neuroticism & -0.06 & 0.05 & 0.02 & 76.45 & 0.01 & 0.09 \\
\hline
\end{tabular}

Note: ${ }^{\star} P<0.05{ }^{\star} P<0.01$. 
samples tended to report stronger (negative) effects than studies performed on samples consisting of mostly adolescents and young adults aged $\leq 26$ years old.

Regarding the effects of study nationality, because we could only observe a small number of studies in the middleeast group $(n=3)$, we did not compute the $Q$ test of heterogeneity of effect sizes. Still, for each personality trait, we computed the point estimate of effect-sizes and relative 95\% confidence intervals in each group (see Table S1 in the Supplementary Material). Based on this information, no relevant group-differences emerged.

Next, we examined effects of length of the personality assessment on strength of the association between personality scores, and SmUD scores: no significant moderating effects emerged. Finally, we examined the effect of the year of publication of included studies on the strength of observed effect sizes. Results showed that time of publication was associated with increased strength of the negative association between Conscientiousness and SmUD. Hence, when examining the link between Conscientiousness and SmUD, recent studies tended to report stronger (negative) effects than older studies. No significant moderating effects emerged for the remaining personality traits.

\section{DISCUSSION}

The aim of the present work was to perform a meta-analysis of studies investigating the link between personality and SmUD. In light of available theories on SmUD it has been proposed that from the Big Five of personality, in particular Neuroticism should be positively related to SmUD severity. This association could indeed be observed $(\mathrm{r}=0.25)$ giving support for Billieux's (2012) idea of an existing relationship assurance pathway. In this realm, individuals with higher scores on Neuroticism are more likely to develop higher tendencies towards SmUD due to seeking reaffirmation of being part of a social group via excessively checking social media apps, etc. (e.g., Marengo, Poletti, \& Settanni, 2020). In fact, recent work has supported the relationship between greater levels of excessive reassurance seeking and SmUD severity (Elhai et al., 2020).

The second strongest associations among the Big Five personality traits was an inverse link between Conscientiousness and SmUD severity $(\mathrm{r}=-0.16)$. Such an association was not discussed in the work by Billieux (2012), but appears in the I-PACE model by Brand et al. (2016). In general, we believe such an inverse association to be a good fit with the large body of substance use disorder literature mentioning that individuals with low self-regulation abilities (see also links with low self-directedness out of Cloninger's biosocial theory of personality; Cloninger, 1994) are prone to develop higher addictive tendencies in many areas (Sariyska et al., 2014; Terracciano, Löckenhoff, Crum, Bienvenu, \& Costa, 2008). Not surprisingly, low Conscientiousness has also been linked to lower health behavior (Bogg \& Roberts, 2004). We believe that low Conscientiousness did not appear to be of relevance in Billieux's framework, because such an association has appeared only recently in the literature, due to smartphones probably having developed into more "addictive" devices over time, given the many social media and Freemium games available (Montag, Lachmann, et al., 2019). This idea is supported by our meta-analysis, showing that such Conscientiousness-SmUD associations have been stronger in recent years compared to what has been published in the early years of the smartphone era.

As expected from the model by Billieux (2012), Extraversion was not linked to SmUD in our meta-analysis. Therefore, fulfillment of the urge to communicate and socialize with other individuals via the smartphone (and the respective applications) may not result in addictive behavior related to the smartphone, hence, SmUD. Therefore, social use of the smartphone seems not to contribute to SmUD (Elhai, Hall, et al., 2017; Elhai, Levine, et al., 2017). As regards the Agreeableness and Openness traits, overall associations with SmUD were negative, but small-sized.

The present study also investigated gender- and agerelated differences in the association between personality and SmUD. We did not find indicators of gender differences in the association between personality and SmUD. Regarding age, we found that the negative associations between SmUD and Conscientiousness as well as Agreeableness were stronger in samples including older adults, when compared to samples of adolescents and young adults. These findings may be understood in light of known age-related changes in these personality traits (e.g., both traits are known to be higher among older adults when compared to young adults; Allemand, Zimprich, \& Hendriks, 2008; Donnellan \& Lucas, 2008), and personal responsibilities e.g., work and family responsibilities. Because individuals high on Conscientiousness and Agreeableness are more likely to use problem-focused and social-support coping strategies when dealing with daily stressors (Penley \& Tomaka, 2002), they may be less likely to use technology (e.g., smartphones) as a form of avoidance strategy (Busch, P. A., \& McCarthy, 2020). As individuals enter adulthood, and responsibilities increase, these traits may play a key role in helping them deal more successfully with stress (for such personality changes see Bleidorn, Hopwood, \& Lucas, 2018), and ultimately protect them from developing SmUD.

The present meta-analysis also provided us with the opportunity to investigate potential publication bias in the literature. We failed to find consistent evidence of publication bias for any of the Big Five-SmUD associations. In sum, publication bias does not play a role in the present work. Additionally, from a psychometric point of view, we could not find significant evidence that length of personality assessment affected the strength of association between personality and SmUD.

At the same time, by taking a broad look at existing studies exploring the association between personality and SmUD, the present study was able to highlight existing limitations in the current literature. Our biggest concerns relate to the scarcity of studies recruiting representative samples, as the majority of the studies surveyed in this 
manuscript employed convenience samples. Moreover, there appears to be an overrepresentation of studies performed on samples of university students, typically showing an overrepresentation of women. For this reason, generalizability of results to the general population appears limited. Finally, most of the selected studies were implemented in Englishspeaking or European countries, while studies from other regional and cultural areas were scant, suggesting the need for increased diversity in this research area. This is particularly important given existing known cultural differences in the distribution of personality traits (e.g., Neuroticism, Lynn \& Martin, 1995; Openness, Schmitt, Allik, McCrae, \& BenetMartínez, 2007), and their association with health-related outcomes, potentially including SmUD.

\section{Limitations and directions for future research}

The present work has several limitations. First of all, the present meta-analysis investigated cross-sectional studies. For this reason, it is not clear whether certain personality traits actually result in higher or lower SmUD, or whether such individual differences in personality are a result of the addictive smartphone use. Both directions of effects are possible. For example, spending an increasing amount of time on the smartphone most likely leads to neglecting other duties, e.g., work tasks, which might also result in a less conscientious selfdescription. Nevertheless, personality is rather stable (Edmonds, Jackson, Fayard, \& Roberts, 2008) (but see for recent evidence how personality changes due to critical life events in Bleidorn et al. (2018)) and in line with theory (Billieux, 2012; Brand et al., 2016), we believe the former explanation to be true (i.e., individual differences in personality result in higher or lower SmUD). Still, it must be acknowledged that also in the I-PACE model feedback loops are included, which suggest an effect (not only from personality to SmUD but also) from SmUD on personality. In conclusion, future research should consider adopting a longitudinal approach, as this would help clarify the directions of emerging links between personality and SmUD. A second limitation is the focus of our meta-analysis on the Big Five personality traits. Although the Big Five are the most widely studied traits in the literature dealing with SmUD, a focus on other personality traits can also be important. For example, Billieux (2012) mentioned the relevance of the impulsivity trait, which is not covered in the present work. In detail, Billieux (2012) proposes an impulsive pathway describing individuals with low self-regulation abilities, and heightened risk behavior in the context of smartphones such as using the phone while driving. Another limitation concerns our inability to determine the prevalence of smartphone use in the samples of some of the studies published in early days of the smartphone era, which may have included individuals currently using mobile phones with limited Internet capabilities (i.e., mobile phones using GSM technology). Findings concerning the effect of time of publication on the association between personality and SmUD should be considered in light of this limitation.

Finally, the relatively small number of studies surveyed here limited our ability to detect small-sized moderation effects, leading to low statistical power when performing meta-regressions. As availability of newer studies will increase, the ability to detect these effects will improve. In particular, as noted above, there appears to be a need for more studies performed on samples including a more balanced representation of gender and age groups. Lack of representative samples also represents an important limitation of existing literature, limiting generalizability of results to the general population.

\section{CONCLUSIONS}

Despite these issues, the present meta-analysis observed robust associations of higher Neuroticism and lower Conscientiousness with higher tendencies towards SmUD. The results fit well with the theoretical assumptions of the IPACE model and also in part with Billieux's framework on problematic mobile phone use. These findings indicate that the assessment of personality is of high relevance to understand who in particular is at risk for smartphone overuse. This information could be used to develop prevention programs directed at individuals with personality profiles that might be more vulnerable to develop SmUD. Possibly, interventions should aim at providing at-risk individuals with ways to cope with daily stressors, and consequently negative emotions, as an alternative to using their smartphone and thus ultimately protecting them from developing SmUD.

\section{Funding sources: Nothing declared.}

Authors' contribution: DM, CS, MS and CM designed the present work. DM, CS, MS and CM, contributed to keyword list. DM, CS and DH carried out the literature research. Coding of studies was performed by DC, CS and MS. DM carried out the statistical analysis and wrote the first draft of the methods/results section (this section was worked over by MS). CM drafted the first version of the introduction/discussion sections and the abstract section (which was later worked over by DM and MS). JDE and CS critically worked over the complete paper, which then was approved by all authors.

Conflict of interest: The authors declare no conflict of interest.

\section{SUPPLEMENTARY MATERIAL}

Supplementary data to this article can be found online at https://doi.org/10.1556/2006.2020.00069

\section{REFERENCES}

Agarwald, A., Guyatt, G., \& Busse, J. (2019). Methods commentary: Risk of bias in cross-sectional surveys of attitudes and practices. 
Available at: https://www.evidencepartners.com/wp-content/ uploads/2017/04/Methods-Commentary-Risk-of-Bias-in-crosssectional-surveys-of-attitude.pdf.

Allemand, M., Zimprich, D., \& Hendriks, A. A. J. (2008). Age differences in five personality domains across the life span. Developmental Psychology, 44(3), 758-770.

Andreassen, C. S., Griffiths, M. D., Gjertsen, S. R., Krossbakken, E., Kvam, S., \& Pallesen, S. (2013). The relationships between behavioral addictions and the five-factor model of personality. Journal of Behavioral Addictions, 2(2), 90-99. https://doi.org/ 10.1556/JBA.2.2013.003.

Augner, C., \& Hacker, G. W. (2012). Associations between problematic mobile phone use and psychological parameters in young adults. International Journal of Public Health, 57(2), 437-441. https://doi.org/10.1007/s00038-011-0234-z.

Begg, C. B., \& Mazumdar, M. (1994). Operating characteristics of a rank correlation test for publication bias. Biometrics, 50(4), 1088-1101.

Beranuy, F. M., Chamarro, L. A., Graner, J. C., \& Carbonell, S. X. (2009). Validation of two brief scales for Internet addiction and mobile phone problem use. Piscothema, 21(3), 480-485.

Bian, M., \& Leung, L. (2015). Linking loneliness, shyness, smartphone addiction symptoms, and patterns of smartphone use to social capital. Social Science Computer Review, 33(1), 61-79. https://doi.org/10.1177/0894439314528779.

Bianchi, A., \& Phillips, J. G. (2005). Psychological predictors of problem mobile phone use. CyberPsychology \& Behavior, 8(1), 39-51. https://doi.org/10.1089/cpb.2005.8.39.

Billieux, J. (2012). Problematic use of the mobile phone: A literature review and a pathways model. Current Psychiatry Reviews, 8(4), 299-307. https://doi.org/10.2174/157340012803520522.

Billieux, J., Maurage, P., Lopez-Fernandez, O., Kuss, D. J., \& Griffiths, M. D. (2015). Can disordered mobile phone use be considered a behavioral addiction? An update on current evidence and a comprehensive model for future research. Current Addiction Reports, 2(2), 156-162.

Billieux, J., Schimmenti, A., Khazaal, Y., Maurage, P., \& Heeren, A. (2015). Are we overpathologizing everyday life? A tenable blueprint for behavioral addiction research. Journal of Behavioral Addictions, 4(3), 119-123. https://doi.org/10.1556/2006.4. 2015.009.

Bleidorn, W., Hopwood, C. J., \& Lucas, R. E. (2018). Life events and personality trait change. Journal of Personality, 86(1), 83-96. https://doi.org/10.1111/jopy.12286.

Bogg, T., \& Roberts, B. W. (2004). Conscientiousness and healthrelated behaviors: A meta-analysis of the lading behavioral contributors to mortality. Psychological Bulletin, 130(6), 887919. https://doi.org/10.1037/0033-2909.130.6.887.

Borenstein, M., Hedges, L., Higgins, J., \& Rothstein, H. R. (2005). Comprehensive meta-analysis version 3. Englewood NJ: Biostat. Inc.

Brand, M., Young, K. S., Laier, C., Wölfling, K., \& Potenza, M. N. (2016). Integrating psychological and neurobiological considerations regarding the development and maintenance of specific Internet-use disorders: An Interaction of Person-AffectCognition-Execution (I-PACE) model. Neuroscience \& Biobehavioral Reviews, 71, 252-266. https://doi.org/10.1016/j. neubiorev.2016.08.033.
Busch, P. A., \& McCarthy, S. (2020). Antecedents and consequences of problematic smartphone use: A systematic literature review of an emerging research area. Computers in Human Behavior, 106414. https://doi.org/10.1016/j.chb.2020.106414.

Carvalho, L. F., Sette, C. P., \& Ferrari, B. L. (2018). Problematic smartphone use relationship with pathological personality traits: Systematic review and meta-analysis. Cyberpsychology: Journal of Psychosocial Research on Cyberspace, 12(3), Article 3. https://doi.org/10.5817/CP2018-3-5.

Cho, H.-Y., Kim, D. J., \& Park, J. W. (2017). Stress and adult smartphone addiction: Mediation by self-control, neuroticism, and extraversion. Stress and Health, 33(5), 624-630. https://doi. org/10.1002/smi.2749.

Christal, R. E. (1994). Non-cognitive research involving systems of testing and learning. Final research and development status report (USAF Contract No. F33615-91-D-0010). Armstrong Laboratory, Brooks Air Force Base, United States Air Force.

Cloninger, C. (1994). Temperament and personality. Current Opinion in Neurobiology, 4(2), 266-273.

Cocoradă, E., Maican, C. I., Cazan, A.-M., \& Maican, M. A. (2018). Assessing the smartphone addiction risk and its associations with personality traits among adolescents. Children and Youth Services Review, 93, 345-354. https://doi.org/10.1016/j. childyouth.2018.08.006.

Costa, P. T., Jr., \& McCrae, R. R. (1992). Revised NEO personality inventory (NEO-PI-R) and NEO five-factor inventory (NEOFFI) professional manual. Odessa, FL: Psychological Assessment Resources.

De Pasquale, C., Sciacca, F., Conti, D., Dinaro, C., \& Di Nuovo, S. (2019). Personality and dissociative experiences in smartphone users. Life Span and Disability, 12(1), 129-146. http://shura.shu. ac.uk/24788/.

Delevi, R., \& Weisskirch, R. S. (2013). Personality factors as predictors of sexting. Computers in Human Behavior, 29(6), 25892594. https://doi.org/10.1016/j.chb.2013.06.003.

Demirhan, E., Randler, C., \& Horzum, M. B. (2016). Is problematic mobile phone use explained by chronotype and personality? Chronobiology International, 33(7), 821-831. https://doi.org/10. 3109/07420528.2016.1171232.

Donnellan, M. B., Oswald, F. L., Baird, B. M., \& Lucas, R. E. (2006). The mini-IPIP scales: Tiny-yet-effective measures of the Big Five factors of personality. Psychological Assessment, 18(2), 192-203. https://doi.org/10.1037/1040-3590.18.2.192.

Duke, É., \& Montag, C. (2017a). Smartphone addiction and beyond: Initial insights on an emerging research topic and its relationship to internet addiction. In C. Montag, \& ReuterM. (Eds.), Internet addiction: Neuroscientific approaches and therapeutical implications including smartphone addiction (S. 359372). Springer International Publishing. https://doi.org/10. 1007/978-3-319-46276-9_21.

Duke, É., \& Montag, C. (2017b). Smartphone addiction, daily interruptions and self-reported productivity. Addictive Behaviors Reports, 6, 90-95. https://doi.org/10.1016/j.abrep.2017.07.002.

Duval, S., \& Tweedie, R. (2000). Trim and fill: A simple funnelplot-based method of testing and adjusting for publication bias in meta-analysis. Biometrics, 56(2), 455-463.

Edmonds, G. W., Jackson, J. J., Fayard, J. V., \& Roberts, B. W. (2008). Is character fate, or Is there hope to change my 
personality yet? Social and Personality Psychology Compass, 2(1), 399-413. https://doi.org/10.1111/j.1751-9004.2007.00037.x.

Ehrenberg, A., Juckes, S., White, K., \& Walsh, S. (2008). Personality and self-esteem as predictors of young people's technology use. Cyberpsychology, Behavior, and Social Networking, 11(6), 739741.

Elhai, J. D., Hall, B. J., Levine, J. C., \& Dvorak, R. D. (2017). Types of smartphone usage and relations with problematic smartphone behaviors: The role of content consumption vs. social smartphone use. Cyberpsychology: Journal of Psychosocial Research on Cyberspace, 11(2).

Elhai, J. D., Levine, J. C., Dvorak, R. D., \& Hall, B. J. (2017). Nonsocial features of smartphone use are most related to depression, anxiety and problematic smartphone use. Computers in Human Behavior, 69, 75-82.

Elhai, J. D., Rozgonjuk, D., Alghraibeh, A. M., Levine, J. C., Alafnan, A. A., Aldraiweesh, A. A., et al. (2020). Excessive reassurance seeking mediates relations between rumination and problematic smartphone use. Bulletin of the Menninger Clinic, $1-19$.

Elhai, J. D., Tiamiyu, M. F., Weeks, J. W., Levine, J. C., Picard, K. J., \& Hall, B. J. (2018). Depression and emotion regulation predict objective smartphone use measured over one week. Personality and Individual Differences, 133, 21-28. https://doi.org/10.1016/ j.paid.2017.04.051.

Ezoe, S., Toda, M., Yoshimura, K., Naritomi, A., Den, R., \& Morimoto, K. (2009). Relationships of personality and lifestyle with mobile phone dependence among female nursing students. Social Behavior and Personality, 37(2), 231-238. https://doi.org/ 10.2224/sbp.2009.37.2.231.

Fu, R., Gartlehner, G., Grant, M., Shamliyan, T., Sedrakyan, A., Wilt, T. J., et al. (2011). Conducting quantitative synthesis when comparing medical interventions: AHRQ and the Effective Health Care Program. Journal of Clinical Epidemiology, 64(11), 1187-1197.

Gao, Q., Jia, G., Fu, E., Olufadi, Y., \& Huang, Y. (2020). A configurational investigation of smartphone use disorder among adolescents in three educational levels. Addictive Behaviors, 103, 106231. https://doi.org/10.1016/j.addbeh.2019.106231.

García-Oliva, C., \& Piqueras, J. A. (2016). Experiential avoidance and technological addictions in adolescents. Journal of Behavioral Addictions, 5(2), 293-303. https://doi.org/10.1556/2006.5. 2016.041.

Goldberg, L. R. (1999). A broad-bandwidth, public domain, personality inventory measuring the lower-level facets of several five-factor models. In Personality psychology in Europe (Bd. 7, S. 7-28). Tilburg University Press.

Gosling, S. D., Rentfrow, P. J., \& Swann, W. B. (2003). A very brief measure of the Big-Five personality domains. Journal of Research in Personality, 37(6), 504-528. https://doi.org/10. 1016/S0092-6566(03)00046-1.

Guazzini, A., Duradoni, M., Capelli, A., \& Meringolo, P. (2019). An explorative model to assess individuals' phubbing risk. Future Internet, 11(1), 21. https://doi.org/10.3390/fi11010021.

Güzeller, C. O., \& Coşguner, T. (2012). Development of a problematic mobile phone use scale for Turkish adolescents. Cyberpsychology, Behavior, and Social Networking, 15(4), 205211. https://doi.org/10.1089/cyber.2011.0210.
Haug, S., Castro, R. P., Kwon, M., Filler, A., Kowatsch, T., \& Schaub, M. P. (2015). Smartphone use and smartphone addiction among young people in Switzerland. Journal of Behavioral Addictions, 4(4), 299-307. https://doi.org/10.1556/ 2006.4.2015.037.

Hedges, L. V., \& Pigott, T. D. (2004). The power of statistical tests for moderators in meta-analysis. Psychological Methods, 9(4), 426-445. https://doi.org/10.1037/1082-989X.9.4.426.

Herrero, J., Urueña, A., Torres, A., \& Hidalgo, A. (2019a). Smartphone addiction: Psychosocial correlates, risky attitudes, and smartphone harm. Journal of Risk Research, 22(1), 81-92. https://doi.org/10.1080/13669877.2017.1351472.

Herrero, J., Urueña, A., Torres, A., \& Hidalgo, A. (2019b). Socially connected but still isolated: Smartphone addiction decreases social support over time. Social Science Computer Review, 37(1), 73-88. https://doi.org/10.1177/0894439317742611.

Horwood, S., \& Anglim, J. (2018). Personality and problematic smartphone use: A facet-level analysis using the five factor model and HEXACO frameworks. Computers in Human Behavior, 85, 349-359. https://doi.org/10.1016/j.chb.2018.04. 013.

Hunter, J. E., Schmidt, F. L., \& Jackson, G. B. (1982). Meta-analysis: Cumulating research findings across studies. SAGE Publications.

Hussain, Z., Griffiths, M. D., \& Sheffield, D. (2017). An investigation into problematic smartphone use: The role of narcissism, anxiety, and personality factors. Journal of Behavioral Addictions, 6(3), 378-386. https://doi.org/10.1556/2006.6. 2017.052.

Hwang, Y., \& Jeong, S.-H. (2015). Predictors of parental mediation regarding children's smartphone use. Cyberpsychology, Behavior, and Social Networking, 18(12), 737-743. https://doi. org/10.1089/cyber.2015.0286.

Jenkins, D. G., \& Quintana-Ascencio, P. F. (2020). A solution to minimum sample size for regressions. PLoS One, 15(2), e0229345. https://doi.org/10.1371/journal.pone.0229345.

John, O. P., Naumann, L. P., \& Soto, C. J. (2008). Paradigm shift to the integrative Big Five trait taxonomy. In O. P. John, R. W. Robins, \& L. A. Pervin (Eds.), Handbook of personality: Theory and research (3. Aufl.). Guilford Press.

Karadağ, E., Tosuntaş, Ş. B., Erzen, E., Duru, P., Bostan, N., Şahin, B. M., et al. (2015). Determinants of phubbing, which is the sum of many virtual addictions: A structural equation model. Journal of Behavioral Addictions, 4(2), 60-74. https://doi.org/ 10.1556/2006.4.2015.005.

Kita, E., \& Luria, G. (2018). The mediating role of smartphone addiction on the relationship between personality and young drivers' smartphone use while driving. Transportation Research Part F: Traffic Psychology and Behaviour, 59, 203-211. https:// doi.org/10.1016/j.trf.2018.09.001.

Kruger, D. J., \& Djerf, J. M. (2017). Bad vibrations? Cell phone dependency predicts phantom communication experiences. Computers in Human Behavior, 70, 360-364. https://doi.org/10. 1016/j.chb.2017.01.017.

Kuss, D. J., Harkin, L., Kanjo, E., \& Billieux, J. (2018). Problematic smartphone use: Investigating contemporary experiences using a convergent design. International Journal of Environmental Research and Public Health, 15(1), 142. https://doi.org/10.3390/ ijerph15010142. 
Kwon, M., Kim, D.-J., Cho, H., \& Yang, S. (2013). The smartphone addiction scale: Development and validation of a short version for adolescents. PLoS One, 8(12), e83558. https://doi.org/10. 1371/journal.pone.0083558.

Kwon, M., Lee, J.-Y., Won, W.-Y., Park, J.-W., Min, J.-A., Hahn, C., et al. (2013). Development and validation of a smartphone addiction scale (SAS). PloS One, 8(2), e56936. https://doi.org/ 10.1371/journal.pone.0056936.

Laajaj, R., Macours, K., Hernandez, D. A. P., Arias, O., Gosling, S. D., Potter, J., et al. (2019). Challenges to capture the Big Five personality traits in non-WEIRD populations. Science Advances, 5(7), eaaw5226. https://doi.org/10.1126/sciadv.aaw5226.

Lachmann, B., Duke, É., Sariyska, R., \& Montag, C. (2019). Who's addicted to the smartphone and/or the Internet? Psychology of Popular Media Culture, 8(3), 182-189. https://doi.org/10.1037/ ppm0000172.

Lang, F. R., John, D., Lüdtke, O., Schupp, J., \& Wagner, G. G. (2011). Short assessment of the big five: Robust across survey methods except telephone interviewing. Behavior Research Methods, 43(2), 548-567. https://doi.org/10.3758/s13428-011-0066-z.

Lee, E. B. (2015). Too much information: Heavy smartphone and Facebook utilization by African American young adults. Journal of Black Studies, 46(1), 44-61. https://doi.org/10.1177/ 0021934714557034.

Leung, L. (2007). Leisure boredom, sensation seeking, self-esteem, addiction symptoms and patterns of mobile phone use. In E. A. Konijn, M. A. Tanis, S. Utz, \& A. Linden (Eds.), Mediated interpersonal communication. New York, NY: Routledge.

Lin, Y.-H., Chang, L.-R., Lee, Y.-H., Tseng, H.-W., Kuo, T. B. J., \& Chen, S.-H. (2014). Development and validation of the Smartphone Addiction Inventory (SPAI). PLoS One, 9(6). https://doi.org/10.1371/journal.pone.0098312.

Lynn, R., \& Martin, T. (1995). National differences for thirty-seven nations in extraversion, neuroticism, psychoticism and economic, demographic and other correlates. Personality and Individual Differences, 19(3), 403-406.

Marengo, D., Poletti, I., \& Settanni, M. (2020). The interplay between neuroticism, extraversion, and social media addiction in young adult Facebook users: Testing the mediating role of online activity using objective data. Addictive Behaviors, 102, 106150.

McCrae, R. R., \& John, O. P. (1992). An introduction to the fivefactor model and its applications. Journal of Personality, 60(2), 175-215. https://doi.org/10.1111/j.1467-6494.1992.tb00970.x.

Mitchell, L., \& Hussain, Z. (2018). Predictors of problematic smartphone use: An examination of the integrative pathways model and the role of age, gender, impulsiveness, excessive reassurance seeking, extraversion, and depression. Behavioral Sciences, 8, 74. https://doi.org/10.3390/bs8080074.

Moher, D., Shamseer, L., Clarke, M., Ghersi, D., Liberati, A., Petticrew, M., et al. (2015). Preferred reporting items for systematic review and meta-analysis protocols (PRISMA-P) 2015 statement. Systematic Reviews, 4(1), 1.

Montag, C., Bey, K., Sha, P., Li, M., Chen, Y.-F., Liu, W.-Y., et al. (2015). Is it meaningful to distinguish between generalized and specific internet addiction? Evidence from a cross-cultural study from Germany, Sweden, Taiwan and China. Asia-Pacific Psychiatry, 7(1), 20-26. https://doi.org/10.1111/appy.12122.
Montag, C., \& Elhai, J. D. (2019). A new agenda for personality psychology in the digital age? Personality and Individual Differences, 147, 128-134. https://doi.org/10.1016/j.paid.2019.03.045.

Montag, C., Lachmann, B., Herrlich, M., \& Zweig, K. (2019). Addictive features of social media/messenger platforms and freemium games against the background of psychological and economic theories. International Journal of Environmental Research and Public Health, 16(14), 2612. https://doi.org/10. 3390/ijerph16142612.

Montag, C., \& Panksepp, J. (2017). Primary emotional systems and personality: An evolutionary perspective. Frontiers in Psychology, 8, 464. https://doi.org/10.3389/fpsyg.2017.00464.

Montag, C., Schivinski, B., Sariyska, R., Kannen, C., Demetrovics, Z., \& Pontes, H. M. (2019). Psychopathological symptoms and gaming motives in disordered gaming-A psychometric comparison between the WHO and APA diagnostic frameworks. Journal of Clinical Medicine, 8(10), 1691. https://doi.org/10. 3390/jcm8101691.

Montag, C., Wegmann, E., Sariyska, R., Demetrovics, Z., \& Brand, M. (2019). How to overcome taxonomical problems in the study of Internet use disorders and what to do with "smartphone addiction"? Journal of Behavioral Addictions, 1-7. https://doi.org/10.1556/2006.8.2019.59.

Mosalanejad, L., Nikbakht, G., Abdollahifrad, S., \& Kalani, N. (2019). The prevalence of smartphone addiction and its relationship with personality traits, loneliness and daily stress of students in Jahrom University of medical Sciences in 2014: A cross-sectional analytical study. Journal of Research in Medical and Dental Science, 7(2), 131-136.

Müller, M., Brand, M., Mies, J., Lachmann, B., Sariyska, R. Y., \& Montag, C. (2017). The 2D:4D marker and different forms of Internet use disorder. Frontiers in Psychiatry, 8. https://doi.org/ 10.3389/fpsyt.2017.00213.

National Information Society Agency (2011). Research for the development of a smartphone addiction self-assessment scale. Seoul: NIA.

O'Dea, S. (2020). Number of smartphone users worldwide from 2016 to 2021(in billions). Statista. https://www.statista.com/statistics/ 330695/number-of-smartphone-users-worldwide/.

Panda, A., \& Jain, N. K. (2018). Compulsive smartphone usage and users' ill-being among young Indians: Does personality matter? Telematics and Informatics, 35(5), 1355-1372. https://doi.org/ 10.1016/j.tele.2018.03.006.

Panova, T., \& Carbonell, X. (2018). Is smartphone addiction really an addiction? Journal of Behavioral Addictions, 7(2), 252-259. https://doi.org/10.1556/2006.7.2018.49.

Pearson, C., \& Hussain, Z. (2015). Smartphone use, addiction, narcissism, and personality: A mixed methods investigation. International Journal of Cyber Behavior, Psychology and Learning (IJCBPL), 5(1), 17-32. https://doi.org/10.4018/ijcbpl.2015010102.

Peng, S., Zhou, B., Wang, X., Zhang, H., \& Hu, X. (2020). Does high teacher autonomy support reduce smartphone use disorder in Chinese adolescents? A moderated mediation model. Addictive Behaviors, 105, 106319. https://doi.org/10.1016/j.addbeh.2020. 106319.

Penley, J. A., \& Tomaka, J. (2002). Associations among the Big Five, emotional responses, and coping with acute stress. Personality and Individual Differences, 32(7), 1215-1228. 
Peterka-Bonetta, J., Sindermann, C., Elhai, J. D., \& Montag, C. (2019). Personality associations with smartphone and internet use disorder: A comparison study including links to impulsivity and social anxiety. Frontiers in Public Health, 7(127). https:// doi.org/10.3389/fpubh.2019.00127.

Pivetta, E., Harkin, L., Billieux, J., Kanjo, E., \& Kuss, D. J. (2019). Problematic smartphone use: An empirically validated model. Computers in Human Behavior, 100, 105-117. https://doi.org/ 10.1016/j.chb.2019.06.013.

Pontes, H. M., Schivinski, B., Sindermann, C., Li, M., Becker, B., Zhou, M., et al. (2019). Measurement and conceptualization of gaming disorder according to the World Health Organization framework: The development of the gaming disorder test. International Journal of Mental Health and Addiction, 1-21. https://doi.org/10.1007/s11469-019-00088-z.

Pontes, H. M., Szabo, A., \& Griffiths, M. D. (2015). The impact of internet-based specific activities on the perceptions of internet addiction, quality of life, and excessive usage: A cross-sectional study. Addictive Behaviors Reports, 1, 19-25. https://doi.org/10. 1016/j.abrep.2015.03.002.

Prasad, S., Harshe, D., Kaur, N., Jangannavar, S., Srivastava, A., Achanta, U., et al. (2018). A study of magnitude and psychological correlates of smartphone use in medical students: A pilot study with a novel telemetric approach. Indian Journal of Psychological Medicine, 40(5), 468-475. https://doi.org/10.4103/IJPSYM.IJPSYM_133_18.

Rammstedt, B., \& John, O. P. (2007). Measuring personality in one minute or less: A 10-item short version of the big five inventory in English and German. Journal of Research in Personality, 41(1), 203-212. https://doi.org/10.1016/j.jrp.2006.02.001.

Rosenthal, R. (1979). The file drawer problem and tolerance for null results. Psychological Bulletin, 86(3), 638-641. https://doi. org/10.1037/0033-2909.86.3.638.

Rozgonjuk, D., Sindermann, C., Elhai, J. D., \& Montag, C. (2020). Fear of missing out (FoMO) and social media's impact on dailylife and productivity at work: Do WhatsApp, Facebook, Instagram and Snapchat use disorders mediate that association?. Addictive Behaviors, 106487.

Samaha, M., \& Hawi, N. S. (2016). Relationships among smartphone addiction, stress, academic performance, and satisfaction with life. Computers in Human Behavior, 57, 321-325. https:// doi.org/10.1016/j.chb.2015.12.045.

Sariyska, R., Reuter, M., Bey, K., Sha, P., Li, M., Chen, Y.-F., et al. (2014). Self-esteem, personality and internet addiction: A crosscultural comparison study. Personality and Individual Differences, 61-62, 28-33. https://doi.org/10.1016/j.paid.2014.01.001.

Saucier, G. (1994). Mini-markers: A brief version of Goldberg's unipolar big-five markers. Journal of Personality Assessment, 63(3), 506-516. https://doi.org/10.1207/s15327752jpa6303_8.

Schmitt, D. P., Allik, J., McCrae, R. R., \& Benet-Martínez, V. (2007). The geographic distribution of Big Five personality traits: Patterns and profiles of human self-description across 56 nations. Journal of Cross-Cultural Psychology, 38(2), 173-212.

Sha, P., Sariyska, R., Riedl, R., Lachmann, B., \& Montag, C. (2019). Linking Internet communication and smartphone use disorder by taking a closer look at the Facebook and WhatsApp applications. Addictive Behaviors Reports, 9, 100148. https://doi.org/ 10.1016/j.abrep.2018.100148.

Smetaniuk, P. (2014). A preliminary investigation into the prevalence and prediction of problematic cell phone use. Journal of Behavioral Addictions, 3(1), 41-53. https://doi.org/10.1556/JBA. 3.2014.004.

Sterne, J. A. C., \& Egger, M. (2001). Funnel plots for detecting bias in meta-analysis: Guidelines on choice of axis. Journal of Clinical Epidemiology, 54(10), 1046-1055. https://doi.org/10. 1016/S0895-4356(01)00377-8.

Takao, M. (2014). Problematic mobile phone use and Big-Five personality domains. Indian Journal of Community Medicine: Official Publication of Indian Association of Preventive \& Social Medicine, 39(2), 111-113. https://doi.org/10.4103/0970-0218. 132736].

Terracciano, A., Löckenhoff, C. E., Crum, R. M., Bienvenu, O. J., \& Costa, P. T. (2008). Five-Factor Model personality profiles of drug users. BMC Psychiatry, 8(1), 22. https://doi.org/10.1186/ 1471-244X-8-22.

Toda, M., Monden, K., Kubo, K., \& Morimoto, K. (2004). Cellular phone dependence tendency of female university students. Nihon Eiseigaku Zasshi, 59(4), 383-386. https://doi.org/10. 1265/jjh.59.383.

Trub, L., \& Barbot, B. (2016). The paradox of phone attachment: Development and validation of the Young Adult Attachment to Phone Scale (YAPS). Computers in Human Behavior, 64, 663672. https://doi.org/10.1016/j.chb.2016.07.050.

Trub, L., \& Barbot, B. (2020). Great escape or path to selfexpression?: Development and validation of a scale of motivations for text messaging. Measurement and Evaluation in Counseling and Development, 53(1), 44-61. https://doi.org/10. 1080/07481756.2019.1667244.

Volungis, A. M., Kalpidou, M., Popores, C., \& Joyce, M. (2019). Smartphone addiction and its relationship with indices of social-emotional distress and personality.International Journal of Mental Health and Addiction. https://doi.org/10.1007/s11469019-00119-9.

Wang, J.-L., Wang, H.-Z., Gaskin, J., \& Wang, L.-H. (2015). The role of stress and motivation in problematic smartphone use among college students. Computers in Human Behavior, 53, 181-188. https://doi.org/10.1016/j.chb.2015.07.005.

Zhitomirsky-Geffet, M., \& Blau, M. (2016). Cross-generational analysis of predictive factors of addictive behavior in smartphone usage. Computers in Human Behavior, 64, 682-693. https://doi.org/10.1016/j.chb.2016.07.061.

Open Access. This is an open-access article distributed under the terms of the Creative Commons Attribution-NonCommercial 4.0 International License (https:// creativecommons.org/licenses/by-nc/4.0/), which permits unrestricted use, distribution, and reproduction in any medium for non-commercial purposes, provided the original author and source are credited, a link to the CC License is provided, and changes - if any - are indicated. 